\title{
Nano Composite Polymer Resin Coating to Control Mild Steel Corrosion in Marine Environment
}

\author{
Athira Rajendran ${ }^{1}$, Thenmozhi Sivalingam ${ }^{2}$, Poongothai Narayanan ${ }^{1}$, \\ Salem Chandrasekaran Murugavel ${ }^{2}$
}

${ }^{1}$ Department of Sciences, Amrita School of Engineering, Coimbatore, India

${ }^{2}$ Department of Chemistry, PSG College of Technology, Coimbatore, India

Email address:

athirarlakshmi $a$ gmail.com (A. Rajendran), npgothai $a$ gmail.com (P. Narayanan)

\section{To cite this article:}

Athira Rajendran, Thenmozhi Sivalingam, Poongothai Narayanan, Salem Chandrasekaran Murugavel. Nano Composite Polymer Resin Coating to Control Mild Steel Corrosion in Marine Environment. American Journal of Applied Chemistry. Vol. 6, No. 3, 2018 , pp. 102-125. doi: 10.11648/j.ajac.20180603.14

Received: May 22, 2018; Accepted: June 12, 2018; Published: July 27, 2018

\begin{abstract}
The present study was carried out to analyze the performance of anti-corrosion property for the combination of PMMA, resin and $\mathrm{ZnO}$ nano particle coating on mild steel in $3.5 \% \mathrm{NaCl}$ medium at $3 \mathrm{hrs}$, 6hrs and $12 \mathrm{hrs}$ exposure. The synthesized nano particle was characterized by FTIR, XRD and SEM analysis. The Polymer + Resin + ZnO (PRZn) combination was coated on MS by dip and spin coating methods. The optimized concentration analyses were verified by visual observation and gravimetric method which were also confirmed by electrochemical studies such as Tafel, AC impedance studies and cyclic voltammetry studies and 10\% PMMA and 10\% PMMA-resin combination was identified as optimum concentration. So, 10\% PMMA-resin combined with $0.1 \mathrm{~g} \mathrm{ZnO}$ was used for further studies and coated on MS and PRZn coating offered almost cent percent corrosion protection of MS upto $12 \mathrm{hrs}$ exposure in $3.5 \% \mathrm{NaCl}$. PRZn coating was characterized by using FTIR, XRD, Zeta potential measurements and thermal stability was analyzed by thermo gravimetric methods. The high I.E offered by the coating material was due to the presence of major constituents that forms a passive film on the metal surface that protects mild steel from corrosion was identified. Profilometer analysis shows that the thickness and roughness of polymer coated specimen is less than paint coated one. Zeta potential and contact angle measurements of the combination coating material shows a protection against corrosion due to more interfacial tension and reduced size of the particles on the metal surface.
\end{abstract}

Keywords: PMMA, Resin, ZnO Nano Particle, Mild Steel, Inhibition Efficiency

\section{Introduction}

Corrosion is the destruction or deterioration of metal because of chemical or electrochemical reaction with its environment. [1] Corrosion acts by itself in multifarious forms in our day to day lives. It causes social consequences such as plant shut down due to failure, loss of efficiency, high maintenance such as painting etc. There is an enhanced increase in usage of all kinds of metals in all fields of technology and the protection of these metals requires special precautions due to severe corrosion problems in normal atmosphere and marine environment. It is time to check for an alternative way to reduce corrosion to meet current and future environmental limitations. Mild steel is widely used as the constructional material in most of the major industries particularly in food, petroleum, power production, chemical and electrochemical industries, especially due to its excellent mechanical properties and low cost. The major problem of this steel is its dissolution in acidic medium during acid pickling and forms reddish - orange spots and holes in autobodies, leaking hot water tanks, corroded nails etc while exposing in marine environments. [2] The technical option behind the corrosion protection is the cathodic and anodic protection, materials selection, application of internal and external coatings etc. One of the new effective methods is having non-toxic coating systems. Protective coatings generally act as a barrier and it isolate the corroding metal from its environment where the polymers with nano $\mathrm{ZnO}$ composite due to its own redox activity present in the 
coatings passives the metal surface at pinhole areas immediately.[3]Among many methods of coating technology available, dip and spin coatings are simple, economical and reliable one. Dip coating is the precision controlled immersion and withdrawal of any substrate into a reservoir of liquid for the purpose of depositing a layer of material. Spin coating is a procedure used to deposit uniform thin films to flat substrates where a thickness of coating less than $200 \mathrm{~nm}$ is desirable and to produce a coating with such thickness, dilute solutions of polymer is used. [4] Polymeric coatings are coatings or paint made with polymers that provide superior adherence and protection from corrosion. Polymer (Poly methyl methacrylate-PMMA) mainly used as coating material, swells and dissolves in many of the organic solvents and hence chloroform is chosen as the solvent for the present study. [5] So the use of PMMA polymer material has expected to enhance the corrosion resistance property with nano $\mathrm{ZnO}$. Epoxy resin having high adherent property and while mixing with polymer and nano $\mathrm{ZnO}$, it is expected to provide highly adherent durable film on metal surface in severe corrosive marine environment.[6] So, a new corrosion protection coating material having a combination of polymerresin- $\mathrm{ZnO}$ (PRZn) is used in the present study, where the prepared solution is expected to effectively increase the corrosion resistant activity providing an adherent thin film coating on mild steel due to combined effect (synergetic effect) of PMMA with high durability with self- healing properties in $\mathrm{NaCl}$ environment.

\section{Experimental Section}

\subsection{Materials and Chemicals}

Mild steel (MS) specimens were cut into pieces having area $5 \mathrm{~cm} \times 1 \mathrm{~cm}$ which had a percent nominal composition as measured by vacuum emission spectrometer DV-4, (PRICOL, Coimbatore, Tamil Nadu, India) of C -0.06, Mn- 0.4, Si- 0.05, P- 0.03, S- 0.0277, Cr- 0.022, Mo - 0.014 and Ni- 0.0117. The specimen were polished to obtain a smooth surface using different grade emery papers (No. $1 / 0$ to 4/0) and were degreased with CLARKS solution (50g of stannous chloride + $20 \mathrm{~g}$ of antimony trioxide in $1000 \mathrm{~mL}$ of conc. $\mathrm{HCl}$ ), followed by washing with tap water followed by distilled water, dried and stored in a dissector for further study.

More $\mathrm{NaCl}$ is produced and utilized than any other chemicals in the world. $\mathrm{NaCl}$ plays a vital commodity in the world. It is widely used for chemical cleaning process of steel, feed stocks and chemical syntheses. Due to tremendous increase in usage of MS in industrial activities, and around $60 \%$ land portion is covered with sea water but marine environment is highly corrosive and even very high for MS. So for present study $3.5 \% \mathrm{NaCl}$ solution concentration was prepared to create marine environment and exposing the coated specimens and corrosion inhibition efficiency of the coated material was studies.

PMMA (99\%), Chloroform (95\%), Zinc acetate, Sodium hydroxide and ethanol ACS grade was purchased from
Sigma-Aldrich and were employed as purchase without any further purification. Resin and $\mathrm{ZnO}$ Nano particle were synthesized.

Average molecular weight of the PMMA was determined by using Ostwald's viscosity measurement method. The intrinsic viscosity of polymer sample is measured where the solutions of known concentrations are prepared, and the flow time of solvent and the solutions are measured using the viscometer. In this method the flow times are measured for different known concentration of the PMMA and a graph was plotted between flow time and concentration. The unknown concentration and relative molecular weight was calculated using the Mark Houwink equation:

$$
[\eta]=\mathrm{KM}^{\alpha}
$$

Where $[\eta]=$ intrinsic viscosity, $\mathrm{K}=7.70 * 103$ (constant), $\alpha$ $=0.70$ (constant). The average molecular weight of the polymer was calculated as $57,753 \mathrm{~g} / \mathrm{mol}$.

\subsection{Preparation of PMMA (P)}

PMMA polymer solutions of different concentration of $1 \%, 5 \%, 10 \%, 15 \%$, and $20 \%$ were prepared using chloroform as the solvent. The solution was stirred using a magnetic stirrer for 3 hours at $700 \mathrm{rpm}$ at $40^{\circ} \mathrm{C}$ and further sonicated to obtain homogenous solution using an Ultra Sonicator instrument for another 30 minutes at $40^{\circ} \mathrm{C}$ and immediately made dip coating on the specimens. The optimum concentration was identified by using dip coated specimen in $3.5 \% \mathrm{NaCl}$ solution by visual observation and weight loss methods. 10\% PMMA concentration was identified as optimum concentration and the same was used for further studies.

\subsection{Synthesis of Resin}

\subsubsection{Synthesis of Cardanol Based Novolac Resin}

Cardanol based Novolac resin was synthesized from (1:0.7) molar ratio of Cardanol to Formaldehyde at $120^{\circ} \mathrm{C}$ using oxalic acid as a catalyst.

\subsubsection{Epoxidation of Novolac Resin}

Synthesized Cardanol based Novolac resin was epoxidized with 3 molar ratio of epichlorohydrin at $120^{\circ} \mathrm{C}$ using sodium hydroxide as a catalyst.

\section{PMMA + RESIN (PR)}

Resin (R) solution of different concentration of $1 \%, 5 \%$, $10 \%, 15 \%$, and $20 \%$ was prepared using chloroform as solvent and mixed with 10\% PMMA solution. The stirring, sonication and dip coating on MS specimen and followed by exposure in $3.5 \% \mathrm{NaCl}$ solution was done as earlier method and $10 \%$ polymer and $10 \%$ resin combination was identified as best protective film offered. So, for further studies $10 \%$ PMMA $+10 \%$ resin (PR) combination was used.

\subsection{Preparation of ZnO Nano Material}

The zinc oxide nano particles were prepared by wet 
chemical method using zinc acetate and sodium hydroxide solutions. Wet chemical synthesis route followed here is chemical precipitation method where it is a simple technique which is given more priority due to its low cost. Some benefits of chemical precipitation method include precise control over the stoichiometry, low temperature and chemical homogeneity during synthesis. Zinc acetate $(0.05 \mathrm{M})$, was prepared and solution was stirred constantly using magnetic stirrer to completely dissolve the zinc acetate for one hour. After complete dissolution of zinc acetate, $0.2 \mathrm{M}$ sodium hydroxide solution was added under constant stirring, drop by drop touching the walls of the vessel. The solution was allowed to settle for overnight, and then nano particles were allowed to heat at $100^{\circ} \mathrm{C}-120^{\circ} \mathrm{C}$ in a hot air oven for $2 \mathrm{hrs}$. Further the nano material was allowed to digest in a Teflon autoclave at $900^{\circ} \mathrm{C}$ for $3 \mathrm{hrs}$ and the supernatant solution was then discarded carefully. Then the remaining solution was centrifuged and filtered and the nano $\mathrm{ZnO}$ was dried in a hot air oven at $100^{\circ} \mathrm{C}-120^{\circ} \mathrm{C}$ for $2 \mathrm{hrs}$. During drying, complete conversion of $\mathrm{Zn}(\mathrm{OH})_{2}$ into $\mathrm{ZnO}$ takes place.

$\mathrm{PMMA}+\mathrm{RESIN}+\mathrm{ZnO}$ coating (PRZn)

Optimized $10 \%$ PMMA $(10 \mathrm{~mL})+10 \%$ resin $(10 \mathrm{~mL})$ solution was mixed with $0.1 \mathrm{~g}$ of synthesized nano $\mathrm{ZnO}$ (PRZn) and stirred for $3 \mathrm{hrs}$ at room temperature and sonicated for another 30 minutes at $40^{\circ} \mathrm{C}$ and dip coating was carried out immediately on MS specimen surface and exposed in $3.5 \% \mathrm{NaCl}$ solution.

\subsection{Methods of Coating Techniques on Metal Surface}

\subsubsection{Dip Coating}

It is the controlled immersion and withdrawal of a substrate into a reservoir of liquid. Metal specimens were allowed to have dip coating using the solutions of different concentrations which were prepared in a closed beaker. They were allowed to have dip coating for duration of 30 seconds for a maximum of 3 times at room temperature followed by air drying. PR specimens and PRZn specimens after dip coating were air dried for 7 days and further annealed at $40^{\circ} \mathrm{C}$ for 10 minutes and $50^{\circ} \mathrm{C}$ for 30 minutes in a hot air oven and tested for corrosion resistant studies.

\subsubsection{Spin Coating}

The solution combinations for spin coating, the stirring processes carried out for $24 \mathrm{hrs}$ and sonication was done for $3 \mathrm{hrs}$ at $40^{\circ} \mathrm{C}$ by using the same instruments.

Prepared solutions were allowed to have spin coating on the metal specimens using the instrument ESPIN NANO having the solution in syringe volume of $5 \mathrm{~mL}$ with the flow rate of $1 \mathrm{~mL}$ per hour for duration of $5 \mathrm{hrs}$ and applying a voltage of $20 \mathrm{kV}$. It deposits a uniform thin nano fiber film on flat metal substrates.

\subsection{Characterization}

\subsubsection{XRD}

$\mathrm{X}$ ray powder diffraction $(\mathrm{XRD})$ pattern was recorded for the coated specimen using Rigaku Model Ultima IV instrument with $\mathrm{Cu} \mathrm{K}$ alpha radiation (Philips, Eindhoven, Netherlands). The spectrum was plotted between intensity and $2 \theta$ values. For both XRD and FTIR methods, the spectrum were recorded for $10 \%$ PRZn film having dip and spin coated on MS sample after dried and the surface was carefully scratched off. For ZnO Nano particle, the spectrum was recorded for the synthesized dry powder.

\subsubsection{FTIR}

The FTIR spectra of the synthesized $\mathrm{ZnO}$ nano particle and $10 \%$ PRZn samples were recorded by using FTIR spectrophotometer (Shimadzu, Japan) from the range of $4000-500 \mathrm{~cm}^{-1}$ as $\mathrm{KBr}$ pellets. The scratched thin film was then mixed with $\mathrm{KBr}$ and made into pellets and the FTIR spectrum was recorded between percentage transmission and wave number.

\subsubsection{Zeta Potential and Particle Size Distribution}

Zeta potential is an electrochemical aspect of a particle's surface, and information about a particle's dispersibility, aggregability, and adhesion ability obtained from this measurement. If zeta potential takes a cross value of around zero, the repulsive force between particles becomes weak and the particles eventually aggregates. So, Zeta potential of PRZn combination was measured using Zeta Potential analyzer (Zetasizer Ver. 6.32, USA) at room temperature in the count rate of $15.6 \mathrm{kcps}$ in the measurement position of $4.65 \mathrm{~mm}$ for the duration of $1 / 2 \mathrm{hr}$.

\subsubsection{Visual Observation}

In order to analyze the optimum concentration of the solutions to provide high corrosion resistant for dip coated MS specimens in $3.5 \% \mathrm{NaCl}$ medium were analyzed by visual observation method. Different concentration of $1 \%$, $2 \%, 5 \% 10 \%, 15 \%$ and $20 \%$ polymer solutions were prepared and coated on MS and exposed in 3.5\% $\mathrm{NaCl}$ medium for $3 \mathrm{hrs}, 6 \mathrm{hrs}$ and $12 \mathrm{hrs}$. The optimum concentration of PR and PRZn was also analyzed by the same procedure after dip coating the specimens were dried at room temperature for 7 days followed by annealing at $40^{\circ} \mathrm{C}$ for duration of $4 \mathrm{hrs}$ and exposing it $3.5 \% \mathrm{NaCl}$ solution in $3 \mathrm{hrs}$, $6 \mathrm{hrs}$ and $12 \mathrm{hrs}$.

\subsubsection{Weight Loss Method}

The coated and uncoated (blank) MS specimens were weighed and three specimen were immersed in $100 \mathrm{~mL}$ of this electrolyte solution $(3.5 \% \mathrm{NaCl})$ for a constant time of $3 \mathrm{hrs}$, $6 \mathrm{hrs}$ and $12 \mathrm{hrs}$ to carry out the experiments in triplicates at $25^{\circ} \mathrm{C}$; were taken out and washed thoroughly with tap water followed by rinsed with distilled water, dried and reweighed. The difference in weight gives weight loss for varying concentration $(1 \%, 2 \%, 5 \%, 10 \% \& 15 \%)$ and inhibition efficiency (I. E.) was calculated using the equation:

$$
\text { I. } \mathrm{E} .=\frac{\mathrm{W} 0-\mathrm{W}}{W 0} \times 100
$$

Where, $\mathrm{W}_{\mathrm{o}} \& \mathrm{~W}$-weight loss without \& with coating. 


\subsubsection{Potentiodynamic Polarization Methods}

Polarization studies of Tafel plot, AC Impedance studies and cyclic voltammetry were carried out using $\mathrm{CH} 660$ electrochemical work station. A three electrode assembly of MS as working electrode, saturated calomel electrode (SCE) as reference and platinum as auxiliary electrode was used.10 $\mathrm{mL}$ of $3.5 \% \mathrm{NaCl}$ was taken in a $10 \mathrm{~mL}$ beaker, then a polished electrode (mild steel with diameter $0.2 \mathrm{~cm} \mathrm{x} 0.2 \mathrm{~cm}$ ) was introduced and allowed to attain a constant potential for 15 mins. The counter electrode is placed at $+0.5 \mathrm{~V}$ cathodic to its open circuit potential (OCP).

(i). Tafel plot.

Tafel plot performed on sample by polarizing about $3 \mathrm{~V}$ anodically with the potential scan rate of $0.2 \mathrm{~V} / \mathrm{s}$. From the polarization study, corrosion parameters such as corrosion potential $\left(\mathrm{E}_{\text {corr }}\right)$, corrosion current $\left(\mathrm{I}_{\text {corr }}\right)$, and inhibition efficiency (I.E) was calculated.

(ii). Impedance spectrophotometry.

Impedance measurements were carried out with the same instrument that was used for Tafel method and the cell set up similarly. At each corrosion potential, an AC sine wave of $0.005 \mathrm{~V}$ amplitude is applied to the electrode with the frequency of $10000 \mathrm{~Hz}$ to $0.1 \mathrm{~Hz}$ and it was super imposed at it OCP. In this method the charge transfer resistance $\left(\mathrm{R}_{\mathrm{ct}}\right)$ is obtained at various frequency from the plots of $Z^{\prime}$ (real parts) vs Z" (imaginary part) from Nyquist plots. The value $\left(R_{p}+\right.$ $R_{s}$ ) corresponds to the points where the plot cuts Z- axis at low frequency and solution resistant $\left(R_{s}\right)$ corresponds to the point where the half wave semicircle cuts the Z-axis at high frequency and the difference gives the polarization resistant $\left(\mathrm{R}_{\mathrm{p}}\right)$ values.

(iii). Cyclic voltammetry.

The electrochemical stability of the P, PR and PRZn coating was evaluated by using cyclic voltammetry (CV) measurements. The counter electrode is placed between +0.3 $\mathrm{V}$ and $-0.1 \mathrm{~V}$ to its open circuit potential (OCP). The CV plot was performed on the sample with the potential scan rate of $0.05 \mathrm{~V} / \mathrm{s}$ with 2 sweep segments. From the study, parameters such as potential $\left(\mathrm{E}_{\text {corr }}\right)$, current $\left(\mathrm{I}_{\text {corr }}\right)$ and I.E were calculated for the blank and coated samples in $3.5 \% \mathrm{NaCl}$.

(iv). Reproducibility Test.

Reproducibility is the ability of an entire study to be duplicated/ triplicate and it is one of the best scientific method to evaluate reliability of the result. The reproducibility of the specimens was analyzed using the different techniques viz. Tafel, AC impedance and cyclic voltammetry methods. Same dip coated metal specimens using fresh electrolyte solution of $3.5 \% \mathrm{NaCl}$ each time at room temperature was analyzed for three times.

\subsubsection{Comparison of Paint and Dip Coated Specimens}

To evaluate the corrosion efficiency, durability of PRZn coated MS specimen over paint coated, a comparison study was carried out. 10\% solutions of PRZn and paint solution were prepared using chloroform as solvent. Prepared PRZn and paint solution was allowed to have a dip coating on MS and dried at room temperature for
$24 \mathrm{hrs}$ and exposed in $3.5 \% \mathrm{NaCl}$ solution for $3 \mathrm{hrs}$, $6 \mathrm{hrs}$ and $24 \mathrm{hrs}$. The efficiency of the coating was compared by visual observation method.

\subsubsection{Thermogravimetric Analysis}

TGA and DTA analysis for the PMMA polymer sample was carried out in $\mathrm{N}_{2}$ atmosphere with a TGA instrument V4 SA- TGA2050 model using thermal advantage software for the data treatment. The heating temperature was in the range between $30-800^{\circ} \mathrm{C}$ at the heating rate of $20^{\circ} \mathrm{C} / \mathrm{min}$.

\subsection{Surface Analysis}

\subsubsection{Profilometer}

A profilometer is a measuring instrument used to measure a surface's profile, in order to quantify its roughness. Critical dimensions as step, curvature, flatness are computed from the surface topography. Profilometer for the dip coated MS were recorded using KLA Tencor where a graph is plotted between thickness and width. Profilometer mainly consist of a detector and a sample stage. Detector determines the point on the sample and sample stage that holds the sample. A contact profilometer has a diamond stylus that physically touches the surface. It is not sensitive to surface color or reflectance.

FESEM and EDX studies were done to analyze surface morphology of metal specimen using the ZEISS SIGMA instrument, Japan.

\subsubsection{FESEM}

FESEM (Field Emission Scanning Electron Microscope) with high resolution instrument was used to study the surface morphologies of the $\mathrm{ZnO}$ nano particle, PRZn dip and spin coated specimen. The acceleration voltage between cathode and anode is commonly in the order of magnitude of 0.5 to $30 \mathrm{kV}$ and the apparatus required an extreme vacuum $\left(10^{-6}\right.$ $\mathrm{Pa}$ ) in the column of the microscope.

\subsubsection{EDX}

Energy dispersive X- ray Spectroscopy (EDX) was used to identify the elemental composition of a cubic micron of sample. This technique works under a sensitivity of $0.1 \%$ for elements heavier than $\mathrm{C}$. It represents the concentrations using a peak with its axis ranging from $0-16 \mathrm{keV}$. MS specimen used for this study was those having $\mathrm{ZnO}$ coated, PRZn dip and spin coated.

\subsubsection{Contact Angle}

The contact angle (C.A) photographs for the coated MS specimen having dip and spin coated with PRZn was recorded using the instrument HO-IAD-CAM 01 and photograph could provide the surface tension of the metal .The wettability of the MS surface was identified by Drop shape analyzer. The shape of the drop was analyzed by measuring the contact angle between water drop and coated metal surface and surface energy was calculated by using the interfacial tension (IFT) values. The IFT values used to measure the strength of contact between solid-liquid phases. 


\section{Results and Discussions}

\subsection{Characterization of Synthesized ZnO Nano Particles}

\subsubsection{XRD}

The $\mathrm{ZnO}$ nano particle was synthesized using Teflon autoclave at $900^{\circ} \mathrm{C}$ and the characterization carried out. The crystal structure of the powdered $\mathrm{ZnO}$ nano particle was analyzed by XRD studies with $\mathrm{Cu} \mathrm{K} \alpha$ radiation $(\kappa=1.5418$ $\mathrm{nm})$. Figure 1 shows the XRD patterns of nano $\mathrm{ZnO}$ particles where, the peaks at $2 \theta=31.672^{\circ}, 34.3^{\circ}, 47.4^{\circ}, 56.5^{\circ}, 62.7^{\circ}$ and $66.2^{\circ}$ were the plan assigned to (110), (002), (103), (200), (112), and (201) of $\mathrm{ZnO}$ nano particles indicating that the sample were poly crystalline wurtzite structure. The pattern found was in well accordance with the JCPDS data. (ZinciteJCPDS-5- 0664) No characteristic peaks with respect to any impurities were detected, suggesting that the high quality of the synthesized $\mathrm{ZnO}$ nano particles. The average crystalline size of nano $\mathrm{ZnO}$ was estimated by Scherrer's formula and estimated to be $80-135 \mathrm{~nm}$.

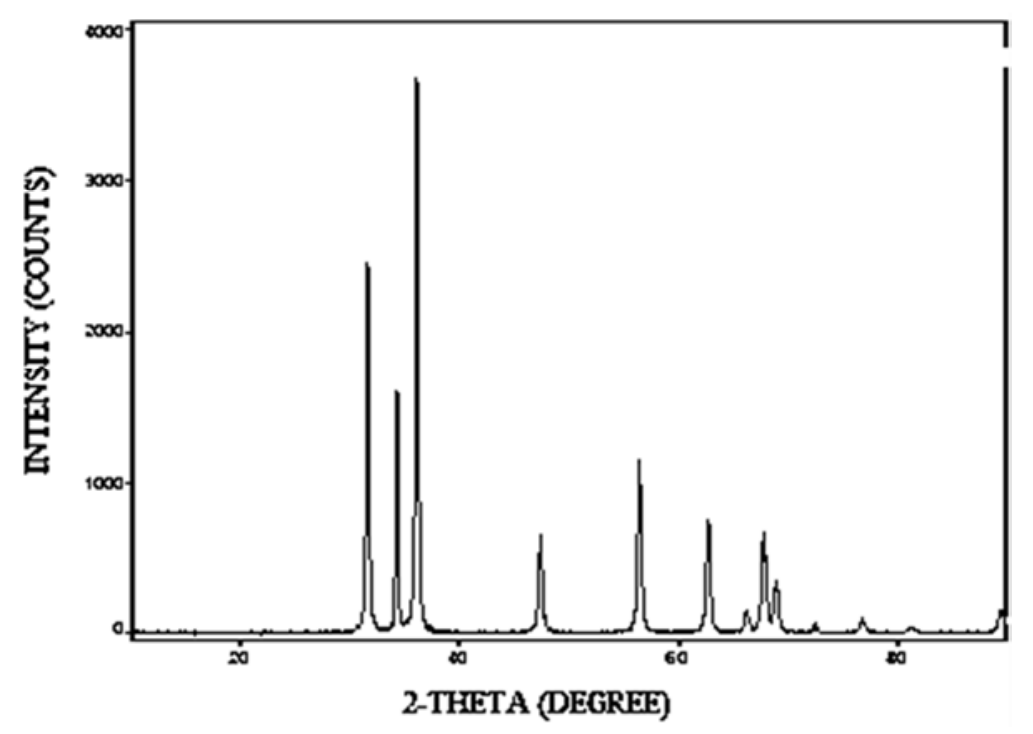

Figure 1. XRD spectra of nanoZnO.

\subsubsection{FESEM}

FESEM micrograph of MS specimen coated with $\mathrm{ZnO}$ nano particle was carried out in the magnification of $43000 \mathrm{X}$ and presented in Figure 2. It clearly identified that $\mathrm{ZnO}$ nano particle having close packed nano coating formed over the $\mathrm{ZnO}$ film surface and the average grain size of the particle is around $127-143 \mathrm{~nm}$ which is concordant with the XRD result of $\mathrm{ZnO}$ films. [7]

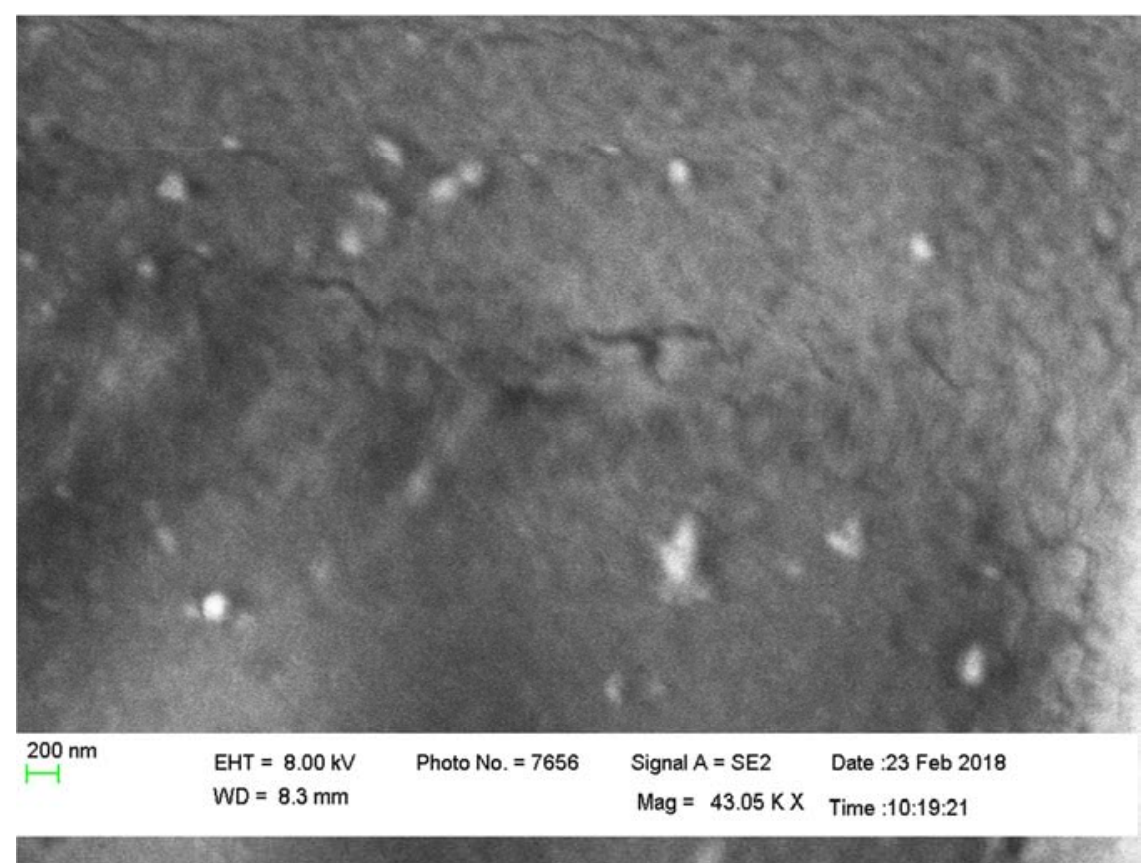

Figure 2. FESEM analysis result for sample coated with synthesized ZnO nano particle. 


\subsubsection{EDX}

The EDX results obtained for $\mathrm{ZnO}$ nano particles coated on MS surface are shown in figures $3 a \& 3 b$ and Table 1 . It is seen that elements of $\mathrm{O}, \mathrm{Zn} \& \mathrm{Fe}$ are identified, where the elements due to nano $\mathrm{ZnO}$ and $\mathrm{MS}$. The percentage composition of $\mathrm{Fe}, \mathrm{O}$ and $\mathrm{Zn}$ is comparable to the major constituents present in $\mathrm{ZnO}$ nano particle. This result is found to be in concordant with the FTIR, XRD and FESEM analysis.
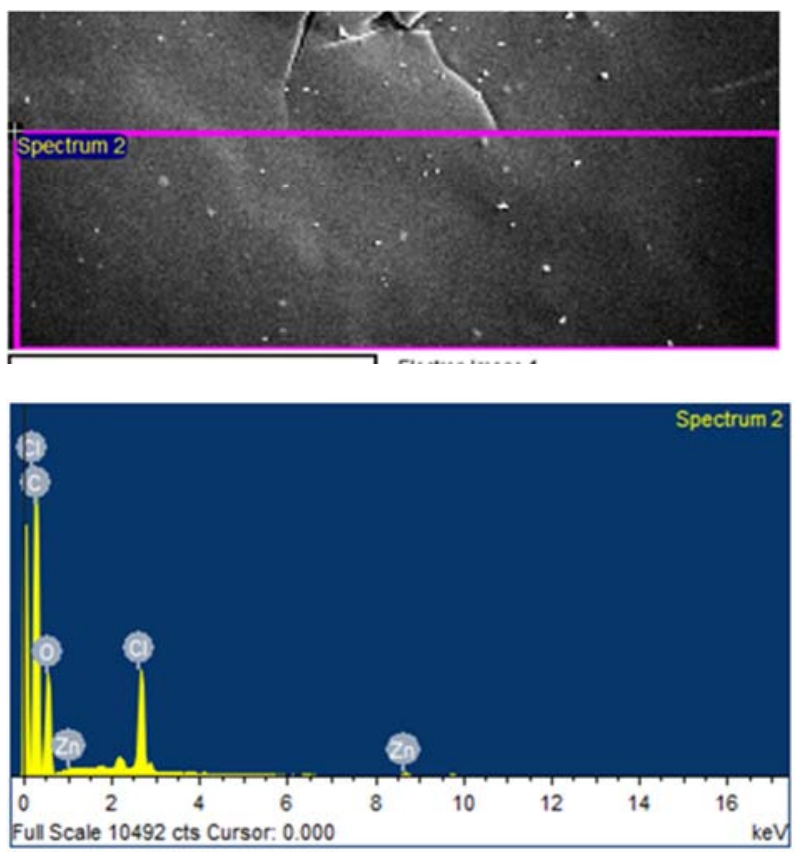

Figure 3. EDX spectra and elemental composition for $\mathrm{ZnO}$ nano particle coated sample.

Table 1. EDX elemental composition of synthesized $\mathrm{ZnO}$ nano particle.

\begin{tabular}{llll}
\hline Element & Weight\% & Atomic\% & Compound\% \\
\hline $\mathrm{Fe}$ & 24.84 & 32.28 & 90.89 \\
$\mathrm{Zn}$ & 4.47 & 1.81 & 0.98 \\
$\mathrm{O}$ & 66.96 & 65.44 & \\
$\mathrm{Au}$ & 1.32 & 0.10 & 1.48 \\
$\mathrm{Total}$ & 100 & & \\
\hline
\end{tabular}

\subsubsection{FTIR}

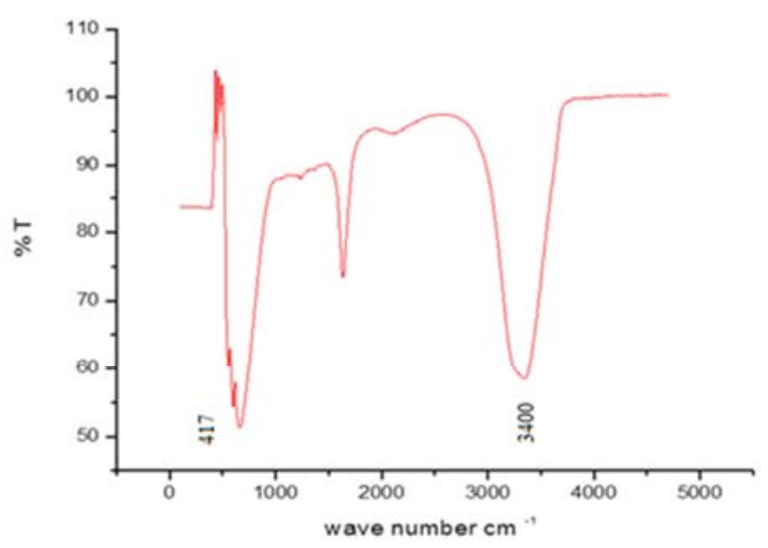

Figure 4. FTIR spectra of ZnO nano particle.
FTIR spectrum of synthesized $\mathrm{ZnO}$ nano particles results is presented in figure 4 . The spectral peak at $3420.90 \mathrm{~cm}^{-1}$ corresponds to the $\mathrm{O}-\mathrm{H}$ stretching vibration while at $417 \mathrm{~cm}^{-1}$ attributes to $\mathrm{Zn}-\mathrm{O}$ that clearly identifies the constituents present in synthesized $\mathrm{ZnO}$ nano particle. [8]

\subsection{Corrosion Monitoring Techniques}

\subsubsection{Visual Observation Method}

Different concentrations of $1 \%, 5 \%, 10 \%, 15 \%$ and $20 \%$ PMMA solution were prepared and dip coated on MS surface and exposed in $3.5 \% \mathrm{NaCl}$ for the period of $3 \mathrm{hrs}$, $6 \mathrm{hrs}$ and $12 \mathrm{hrs}$ at room temperature. By visual observation method the surface of coated MS was compared with the blank. It was inferred that the $10 \%$ polymer coated specimen shows a better corrosion control activity when compared to the blank and other low and high concentration polymer coated specimens. The $10 \%$ coated specimen shows a non -porous adherent coating and peeling off of the specimen was not visualized even after exposed $12 \mathrm{hrs}$, while the other low and high concentration specimens showed a peeling off of the coating from the surface and rusting also taking place.[9] Thus $10 \%$ polymer $(10 \% \mathrm{P})$ concentration was chosen as optimum concentration by visual observation and further it was confirmed by weight loss method.

In order to analyze the optimum concentration of the polymer + resin combination, 10\% PMMA was mixed with different concentration of resin of $1 \%, 5 \%, 10 \%, 15 \%$ and $20 \%$ and dip coated on MS and dried it for 7 days and then exposed in $\mathrm{NaCl}$ for $3 \mathrm{hrs}$, 6hrs and $12 \mathrm{hrs} .10 \%$ PMMA $+10 \%$ resin (PR) combination was visualized better corrosion resistant even after exposed $12 \mathrm{hrs}$. So, this combination was taken as optimum concentration and this result was confirmed with weight loss method. For further studies $10 \%$ PMMA $+10 \%$ resin $+0.1 \mathrm{~g}$ nano $\mathrm{ZnO}$ were mixed and corrosion resistant efficiency was analyzed in $3.5 \% \mathrm{NaCl}$ medium using different techniques.

\subsubsection{Weight Loss Method}

I.E of coated $\mathrm{MS}$ specimens in $3.5 \% \mathrm{NaCl}$ were calculated by using weight loss method at room temperature with different exposure time and presented in Table 2-4. It was observed that blank MS has been severely rusted which is shown by the presence of redbrown rust all over its surface. The weight loss of blank was found to be very high than coated one. Under the same environment in the coated specimen inhibition efficiency was increased upto 10\% PMMA concentration and there after get decreased may be due to peel off of coating film at high concentration and dissolution at low concentration. $10 \%$ PMMA was found to provide maximum inhibition efficiency and hence the same concentration was chosen for further studies. 
Table 2. Inhibition efficiency of PMMA coated $\mathrm{MS}$ in $3.5 \% \mathrm{NaCl}$ at room temperature.

\begin{tabular}{llll}
\hline PMMA & \multicolumn{3}{l}{ Inhibition efficiency (\%) } \\
\cline { 2 - 4 } Concn (\%) & $\mathbf{3 ~ h r s}$ & $\mathbf{6 ~ h r s}$ & $\mathbf{1 2}$ hrs \\
\hline 1 & 85.63 & 82.12 & 71.84 \\
5 & 91.01 & 89.08 & 85.68 \\
10 & 98.30 & 94.56 & 89.08 \\
15 & 94.29 & 89.37 & 86.28 \\
20 & 92.20 & 88.45 & 87.56 \\
\hline
\end{tabular}

Table 3. Inhibition efficiency of $P R$ coated $\mathrm{MS}$ in $3.5 \% \mathrm{NaCl}$ at room temperature.

\begin{tabular}{llll}
\hline \multirow{2}{*}{$\begin{array}{l}\text { Resin conc. } \\
(\%)\end{array}$} & \multicolumn{3}{l}{ Inhibition efficiency (\%) } \\
\cline { 2 - 4 } $\mathbf{3}$ hrs & $\mathbf{6 ~ h r s}$ & $\mathbf{1 2}$ hrs \\
\hline 1 & 80.63 & 76.57 & 69.78 \\
5 & 89.21 & 85.20 & 81.48 \\
10 & 97.45 & 93.23 & 87.28 \\
15 & 92.65 & 87.56 & 84.65 \\
20 & 90.16 & 88.95 & 85.53 \\
\hline
\end{tabular}

Table 4. Inhibition efficiency of PRZn coated $\mathrm{MS}$ in $3.5 \% \mathrm{NaCl}$ at room temperature.

\begin{tabular}{llll}
\hline $\begin{array}{l}\text { Conc. of PR } \\
\text { (\%) }\end{array}$ & \multicolumn{3}{l}{ Inhibition efficiency (\%) } \\
\cline { 2 - 4 } & $\mathbf{3 ~ h r s}$ & $\mathbf{6 ~ h r s}$ & $\mathbf{1 2} \mathbf{~ h r s}$ \\
\hline 1 & 89.90 & 87.45 & 85.42 \\
5 & 92.56 & 90.36 & 88.67 \\
10 & 99.67 & 97.86 & 96.78 \\
15 & 91.67 & 89.65 & 87.43 \\
20 & 90.45 & 88.87 & 89.56 \\
\hline
\end{tabular}

From Table 3 inferred that on addition of different concentrations of resin to the optimized concentration of 10\%PMMA. $10 \%$ PMMA $+10 \%$ resin was showing better inhibition efficiency than other concentrations. High corrosion protection was obtained around $10 \%$ more I.E when PMMA - resin combination than only PMMA coating and also within two weeks peel of taking place in only PMMA coated film, but PR coating offer thin adherent film without peel off even after two months. Thus 10\% PMMA and $10 \%$ resin $(\mathrm{PR})$ was chosen for the further studies.

With PMMA + resin different concentration of $1 \%, 5 \%$, $10 \%, 15 \%$ and $20 \%$ was mixed with $0.1 \mathrm{~g}$ of nano Zno and coated on MS surface, dried and exposed in $3.5 \%$ of $\mathrm{NaCl}$ and the weight loss value obtained used to calculate I.E of the coating and presented in Table 4. 10\%. PRZn is having a maximum inhibition efficiency of $99.67,97.68$ and 96.78 on exposing to electrolyte solution of $3.5 \% \mathrm{NaCl}$ for duration of $3 \mathrm{hrs}, 6 \mathrm{hrs}$ and $12 \mathrm{hrs}$ respectively.

From Table 2 - 4 almost 100\% protections were provided by $10 \%$ PRZn coating than PMMA alone and PR combination. The period of immersion of $3 \mathrm{hrs}, 6 \mathrm{hrs}$ and $12 \mathrm{hrs}$ only slightly vary the I.E values and maximum efficiency of 97 to $99 \%$ was obtained even after exposing $12 \mathrm{hrs}$ of $10 \%$ PRZn combination. From figure 5, the PRZn coated mild steel, specimen surface was observed to have the same brightness even after $12 \mathrm{hrs}$ exposing without any pick of corrosion products or no peel off of film in the severe corrosive medium. But $10 \% \mathrm{P}$ and $10 \%$ PR coated specimen showed slight bulging of film and small pits observed in $3.5 \% \mathrm{NaCl}$ solution with in $3 \mathrm{hrs}$ exposure. These results are evidence of the high protective nature of the PRZn film for compared to P and PR film for long duration in marine environment due to synergistic effect [10] of chemical constituents present in PRZn. Hence the chemical constituent helps the polymer to adhere on metal surface for a long duration without peeling off or dissolution in strong corrosive medium.
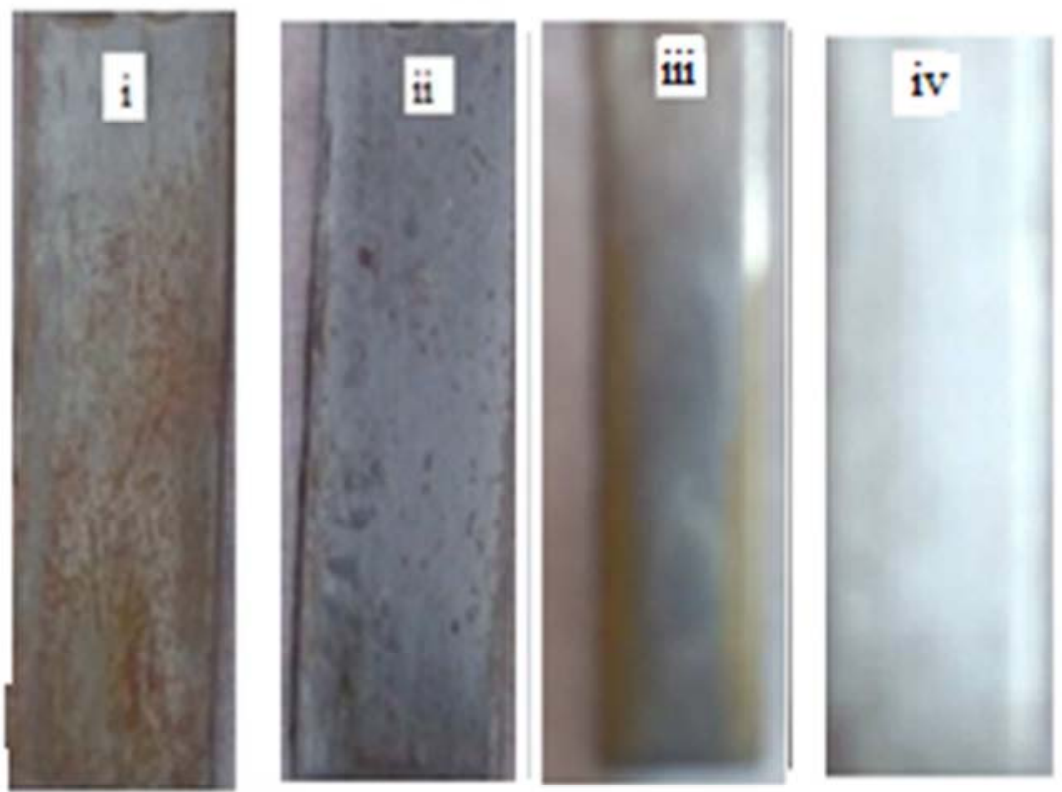

\section{i)BLANK ii)PMMA iii) PMMA -RESIN iv) PMMA-RESIN-ZnO}

Figure 5. Photographs of MS specimens coated with $10 \% \mathrm{P}, 10 \% \mathrm{PR}$ and $10 \% \mathrm{PRZn}$ after exposing for $12 \mathrm{hrs}$ at $25^{\circ} \mathrm{C}$ in $3.5 \% \mathrm{NaCl}$ solution. 


\subsubsection{Potentiodynamic Polarization Studies}

Polarization studies were carried out for P, PR, PRZn coated MS at room temperature for two different concentrations of $10 \%$ \& $15 \%$ in $3.5 \% \mathrm{NaCl}$ environment. Results obtained by Tafel, impedance \& C.V studies are presented in tables and figures. From polarization studies, the corrosion parameters such as $\mathrm{I}_{\text {corr }}, \mathrm{E}_{\text {corr }}$ were deduced and I.E was calculated.

(i). Tafel Study.

From Table 5, it can be noted that $\mathrm{I}_{\text {corr }}$ values for PRZn coated specimens is very low than that for blank. The maximum protection efficiency of $98 \%$ is noted in $3.5 \%$ $\mathrm{NaCl}$ and this observation coincide with the weight loss result. $\mathrm{E}_{\text {corr }}$ values increased for coated specimen over blank. When $10 \%$ resin $\mathrm{ZnO}$ solution is mixed with PMMA, the corrosion resistant values and corrosion potential values increases. A slight shift of $\mathrm{E}_{\text {corr }}$ values to the cathodic side was observed, more for the coated system than blank, inferring that cathodic polarization is more predominant than anodic. These observations clearly indicated that the resin and $\mathrm{ZnO}$ mixed PMMA coating act as mixed type inhibition in $\mathrm{NaCl}$ medium. The Tafel lines in Figure 6 are almost parallel to the blank plot on cathodic side with regular variation, which indicates that the mechanism of cathodic reaction maintain the same after mixing resin $-\mathrm{ZnO}$ solution with PMMA.

Table 5. Potentiodynamic polarization data of $P, P R$ and $P R Z n$ coated on $M S$ in $3.5 \% \mathrm{NaCl}$ at $25^{\circ} \mathrm{C}$.

\begin{tabular}{llll}
\hline Conc & $(-) \mathbf{E}_{\text {corr }}(\mathbf{V})$ & $\mathbf{I}_{\text {corr }}(\mathbf{A})$ & I.E (\%) \\
\hline Blank & 0.7645 & $2.23 * 10^{-4}$ & - \\
$10 \%$ P & 0.4536 & $8.12 * 10^{-6}$ & 92 \\
$15 \%$ P & 0.5464 & $2.55 * 10^{-5}$ & 89 \\
$10 \%$ PR & 0.4536 & $8.22 * 10^{-6}$ & 94 \\
$15 \%$ PR & 0.5443 & $2.43 * 10^{-4}$ & 90 \\
$10 \%$ PRZn & 0.3707 & $4.83 * 10^{-4}$ & 98 \\
$15 \%$ PRZn & 0.5464 & $2.41 * 10^{-3}$ & 89 \\
\hline
\end{tabular}
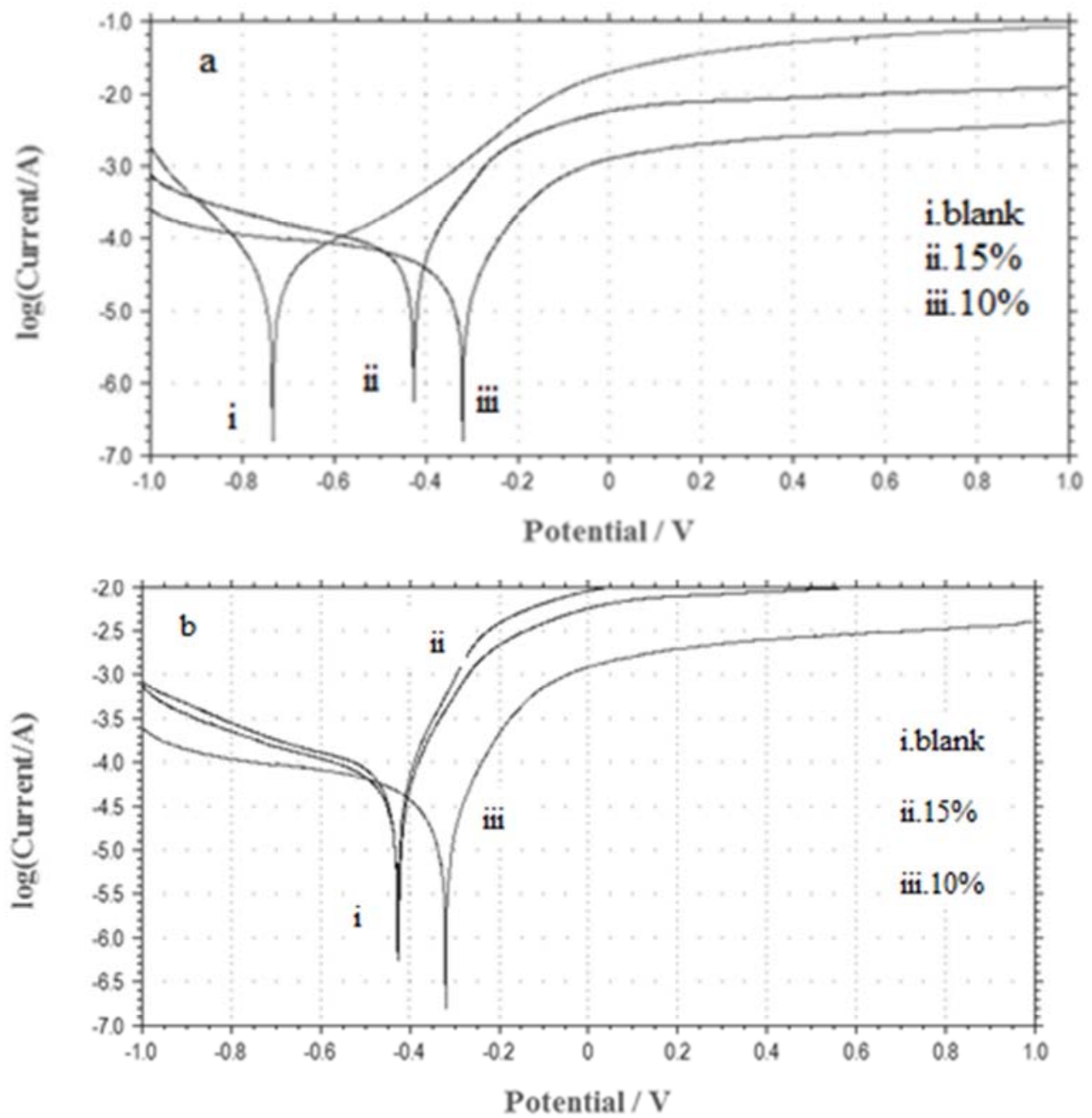


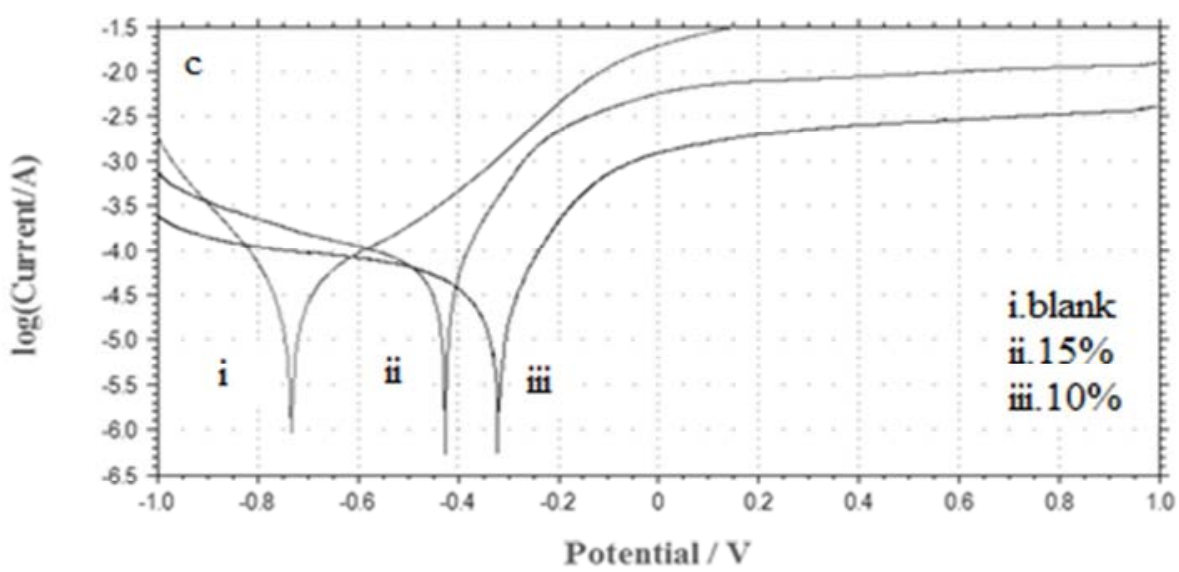

Figure 6. Tafel plot for (a)P,(b)PR,(c)PRZn coated MS in $3.5 \% \mathrm{NaCl}$ at $25^{\circ} \mathrm{C}$.

(ii). AC impedance study

Table 6. Impedance parameters of the P, PR, PRZn coated MS in $3.5 \% \mathrm{NaCl}$ at $25^{\circ} \mathrm{C}$

\begin{tabular}{|c|c|c|c|}
\hline Conc & $\mathbf{R}_{\mathrm{Ct}}\left(\mathrm{Ohm} \mathbf{c m}^{2}\right)$ & $\mathrm{C}_{\mathrm{dl}}\left(\mathrm{Ohm} \mathrm{\textrm {cm } ^ { - 2 } )}\right.$ & I.E (\%) \\
\hline Blank & 10.21 & 0.0085 & - \\
\hline $10 \% \mathrm{P}$ & 98.24 & $2.02 * 10-9$ & 94 \\
\hline $15 \% \mathrm{P}$ & 112.76 & $5.43 * 10-6$ & 85 \\
\hline $10 \% \mathrm{PR}$ & 43.56 & $3.11 * 10-9$ & 96 \\
\hline $15 \% \mathrm{PR}$ & 123.4 & $2.56 * 10-6$ & 91 \\
\hline $10 \%$ PRZn & 32.82 & $6.26 * 10-9$ & 99 \\
\hline $15 \%$ PRZn & 166.3 & $1.30 * 10-6$ & 89 \\
\hline
\end{tabular}
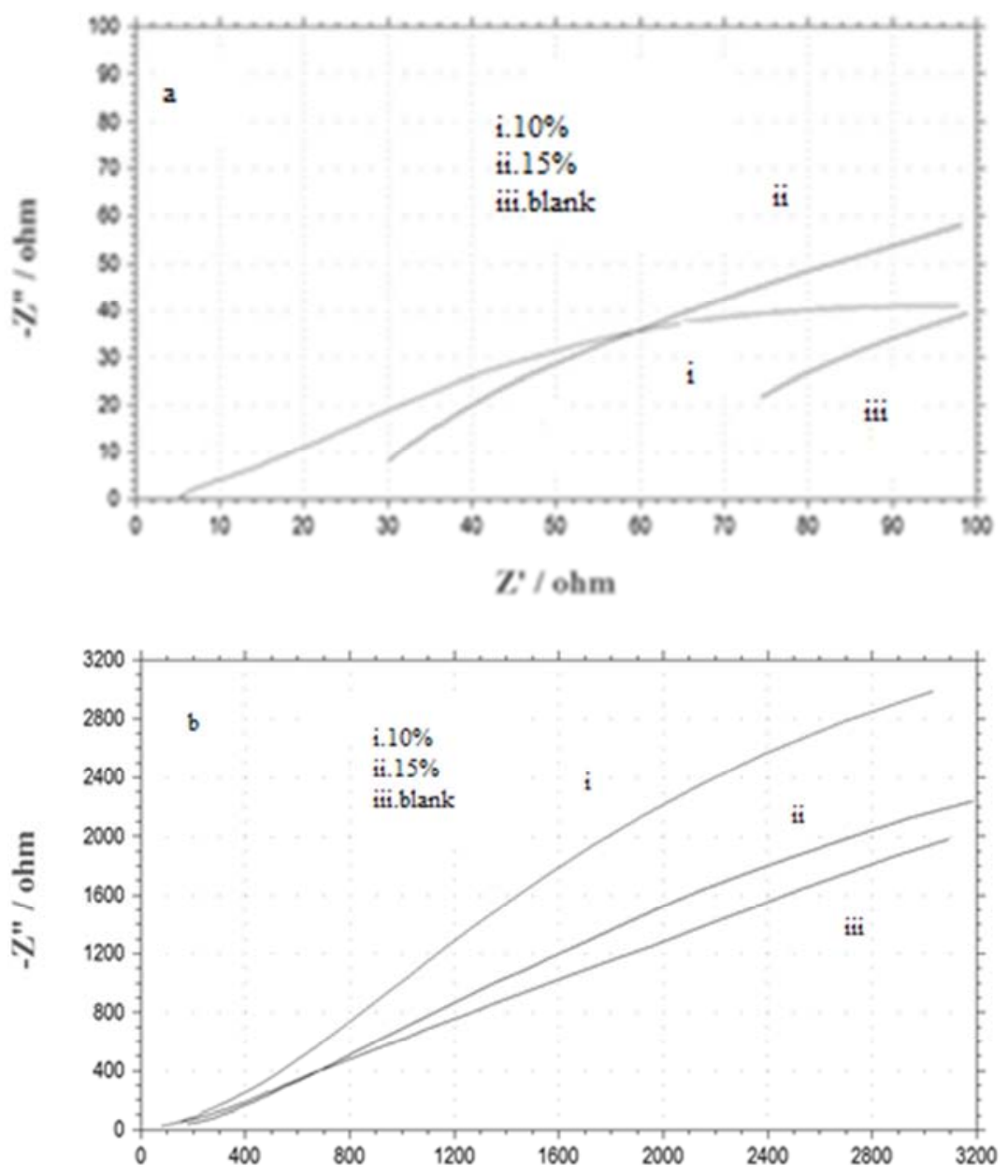


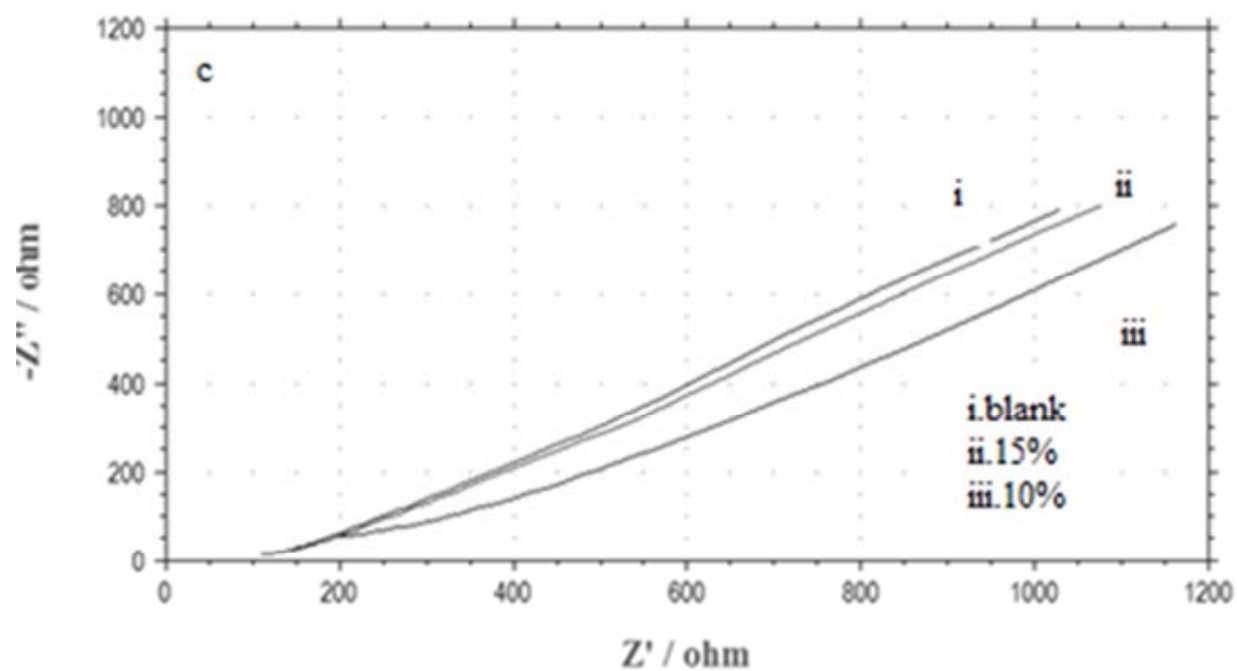

Figure 7. Impedance plot for (a)P, (b)PR, (c)PRZn coated $\mathrm{MS}$ in $3.5 \% \mathrm{NaCl}$ at $25^{\circ} \mathrm{C}$.

The electrochemical impedance analysis was performed in $3.5 \% \mathrm{NaCl}$ for coated and uncoated specimens at room temperature. Figure 7 shows the Nyquist plot of P, PR, and PRZn coated MS specimen as a function of applied potential from high to low frequency. These impedance curves shows an increse in the diametre of the semi circular loop for coated specimens than blank in $\mathrm{NaCl}$ medium. This increase was considerable with increase in the concentration of PMMA. The semi circle of the Nyquist plot were observed not to be much perfect and this deviation is may be due to inhomogenties present in the MS. These data shows that the coating made has protected the corrrosion of MS in $3.5 \%$ $\mathrm{NaCl}$. This is consistent with Tafel \& CV results for which mostly explain the ohmic behaviour nature of coated film for MS. When comparing these figures, it is evident that all the three coatings provides better corrosion resistance in MS in $\mathrm{NaCl}$ medium but PRZn coating provide for long duration. [11]

(iii). Cyclic Voltammetry

Table 7. C. V parameters of theP, PR, PRZn coated $M S$ in $3.5 \% \mathrm{NaCl}$ at $25^{\circ} \mathrm{C}$.

\begin{tabular}{llll}
\hline Conc & $\mathbf{( - )} \mathbf{E}_{\text {corr }}(\mathbf{V})$ & $\mathbf{I}_{\text {corr }}(\mathbf{A})$ & I.E (\%) \\
\hline Blank & 0.0048 & $2.98 * 10^{-3}$ & - \\
$10 \%$ P & 0.0013 & $3.46^{*} 10^{-4}$ & 85 \\
$15 \%$ P & 0.0085 & $1.75^{*} 10^{-2}$ & 65 \\
$10 \%$ PR & 0.0013 & $3.16^{*} 10^{-4}$ & 88 \\
$15 \%$ PR & 0.0085 & $1.35^{*} 10^{-2}$ & 65 \\
$10 \%$ PRZn & 0.0019 & $2.19 * 10^{-4}$ & 92 \\
$15 \%$ PRZn & 0.0076 & $1.44^{*} 10^{-2}$ & 66 \\
\hline
\end{tabular}

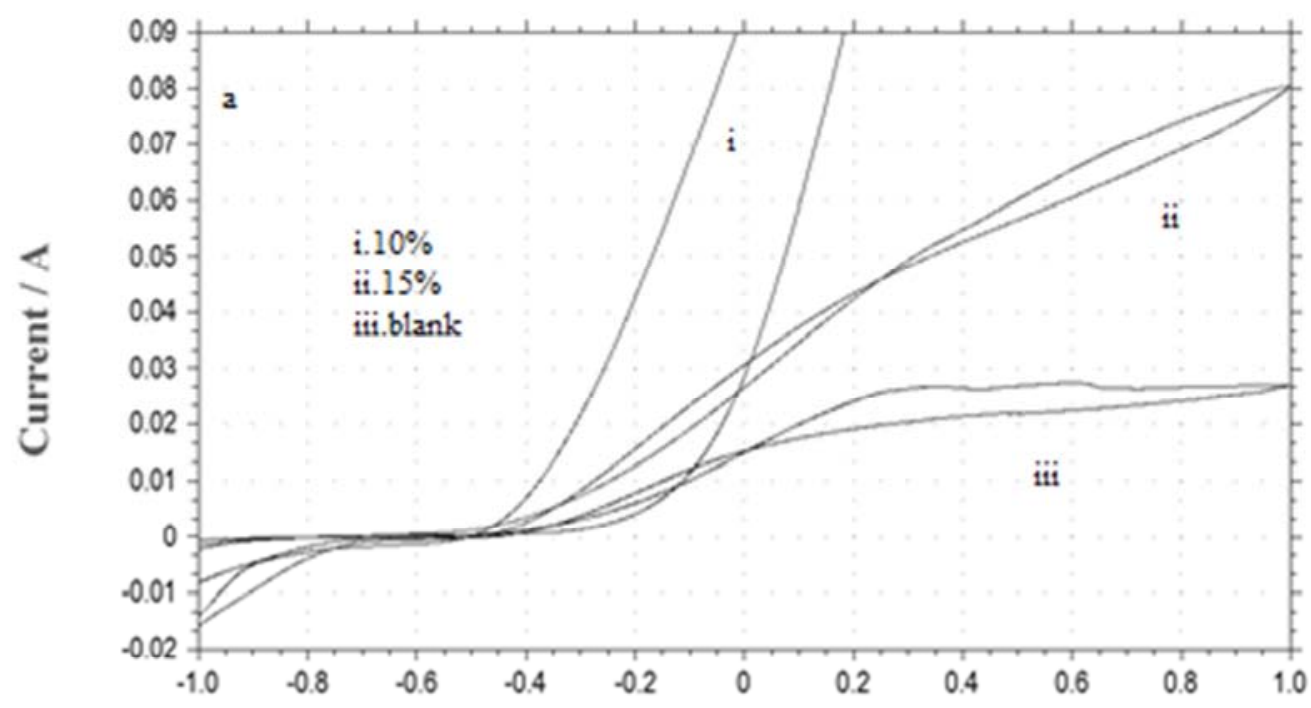

Potential / V 

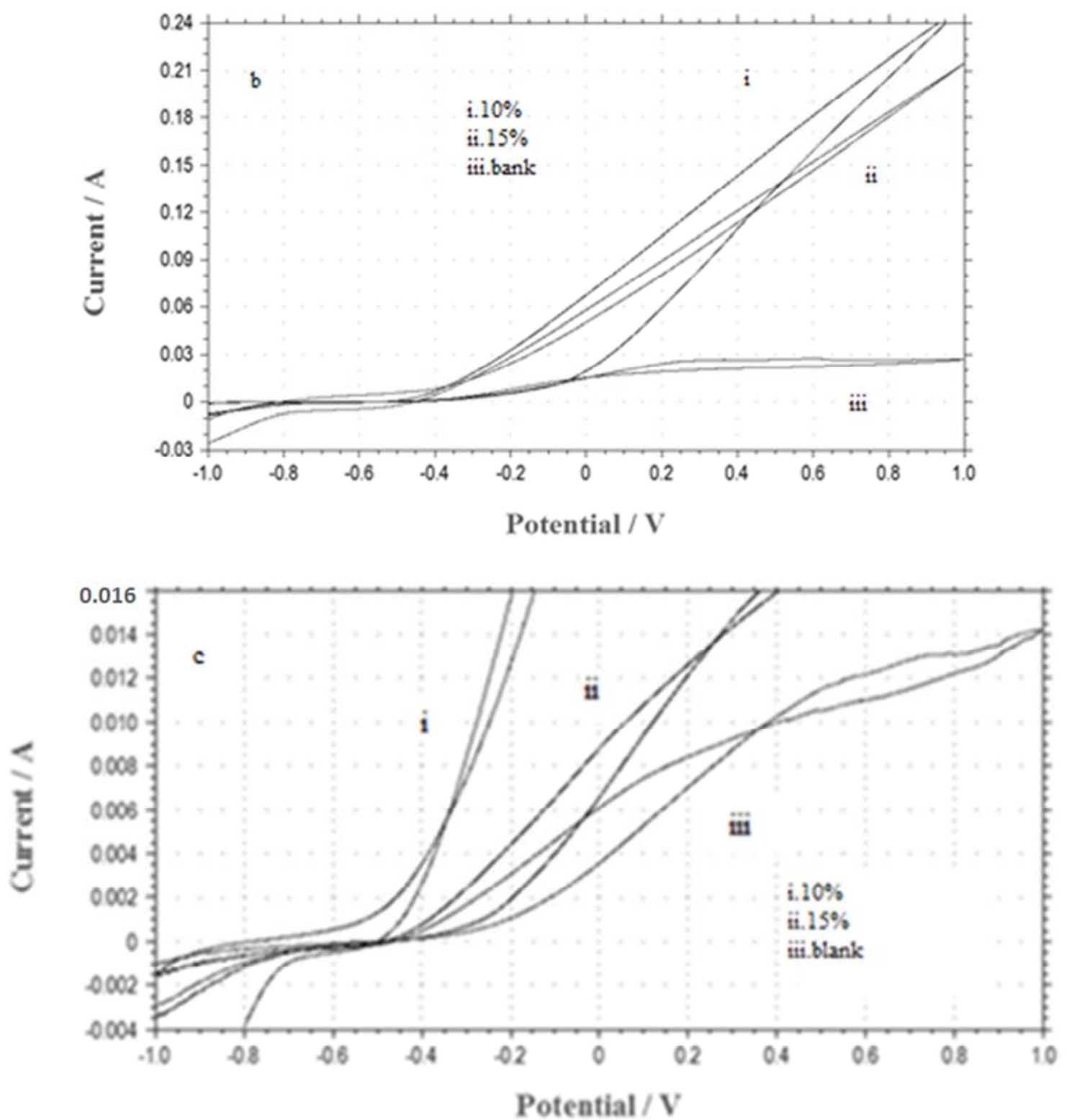

Figure 8. Cyclic Voltammogram for (a) $P$, (b) PR, (c) PRZn coated MS in $3.5 \% \mathrm{NaCl}$ at $25^{\circ} \mathrm{C}$

Figure 8 shows CV curves of $10 \%$ P, $10 \%$ PR and $10 \%$ PRZn coated MS specimens in $3.5 \% \mathrm{NaCl}$ solutions at room temperature. (Figure 8c) shows the CV curve of PRZn coated MS in contact with $3.5 \% \mathrm{NaCl}$ solution, predict the peak values between -0.12 to $+1.0 \mathrm{~V}$ for blank and -0.14 to $+1.3 \mathrm{~V}$ for PRZn coated specimens. Comparison of these responses with other graphs shows larger surface area and larger potential which describes the better reversibility and less ohmic resistance of system for PRZn coated specimen than others coatings in marine environment. CV in all the three P, PR, and PRZn coated specimen shows more ohmic resistance in $\mathrm{NaCl}$ environment than blank. Based on the above discussion, it has estimated that the existence of redox peaks simply illustrate that the coating is active in $\mathrm{NaCl}$ medium is observed.[12].

\subsubsection{Comparison of Dip and Spin Coated Specimens}

Table 8. Potentiodynamic polarization data of P, PR and PRZn dip and spin coated coated on $\mathrm{MS}$ in $3.5 \% \mathrm{NaCl}$ at $25^{\circ} \mathrm{C}$.

\begin{tabular}{|c|c|c|c|}
\hline $10 \%$ Conc & $(-) E_{\text {corr }}(V)$ & $I_{\text {corr }}(\mathrm{A})$ & I. E (\%) \\
\hline Blank & 0.7645 & $2.23 * 10^{-4}$ & - \\
\hline P dip coated & 0.4536 & $8.12 * 10^{-6}$ & 92 \\
\hline P spin coated & 0.5464 & $8.55^{*} 10^{-6}$ & 94 \\
\hline PR spin coated & 0.6443 & $7.93 * 10^{-6}$ & 96 \\
\hline PRZn dip coated & 0.4807 & $4.43 * 10^{-4}$ & 97 \\
\hline PRZn spin coated & 0.6964 & $4.81 * 10^{-4}$ & 99 \\
\hline
\end{tabular}



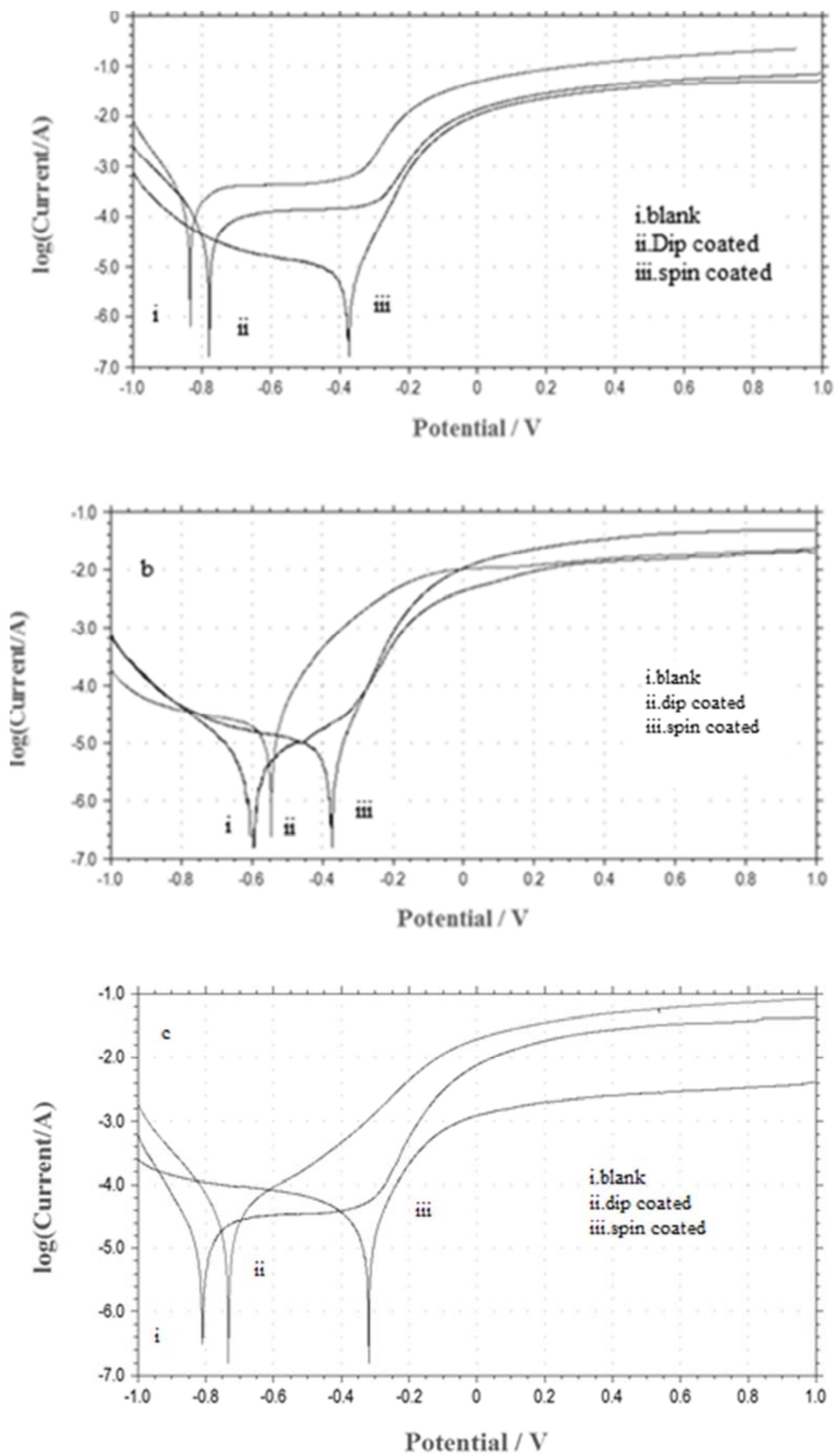

Figure 9. Tafel plot for (a)P,(b)PR, (c)PRZn dip and spin coated $M S$ in $3.5 \% \mathrm{NaCl}$ at $25^{\circ} \mathrm{C}$. 
Table 9. Impedance parameters of the P, PR, PRZn dip and spin coated $\mathrm{MS}$ in $3.5 \% \mathrm{NaCl}$ at $25^{\circ} \mathrm{C}$.

\begin{tabular}{|c|c|c|c|}
\hline $10 \%$ Conc & $\mathbf{R}_{\mathrm{Ct}}\left(\mathrm{Ohm} \mathrm{cm}^{2}\right)$ & $\mathrm{C}_{\mathrm{dl}}\left(\mathrm{Ohm} \mathrm{\textrm {cm } ^ { - 2 } )}\right.$ & I. E (\%) \\
\hline Blank & 10.21 & 0.0085 & - \\
\hline P dip coated & 98.24 & $2.02 * 10^{-9}$ & 94 \\
\hline P spin coated & 112.76 & $3.43 * 10^{-9}$ & 96 \\
\hline PR dip coated & 43.56 & $3.11 * 10^{-9}$ & 96 \\
\hline PR spin coated & 123.4 & $3.56 * 10^{-9}$ & 97 \\
\hline PRZn dip coated & 32.82 & $6.26 * 10^{-9}$ & 98 \\
\hline PRZn spin coated & 166.1 & $7.10 * 10^{-9}$ & 99 \\
\hline
\end{tabular}
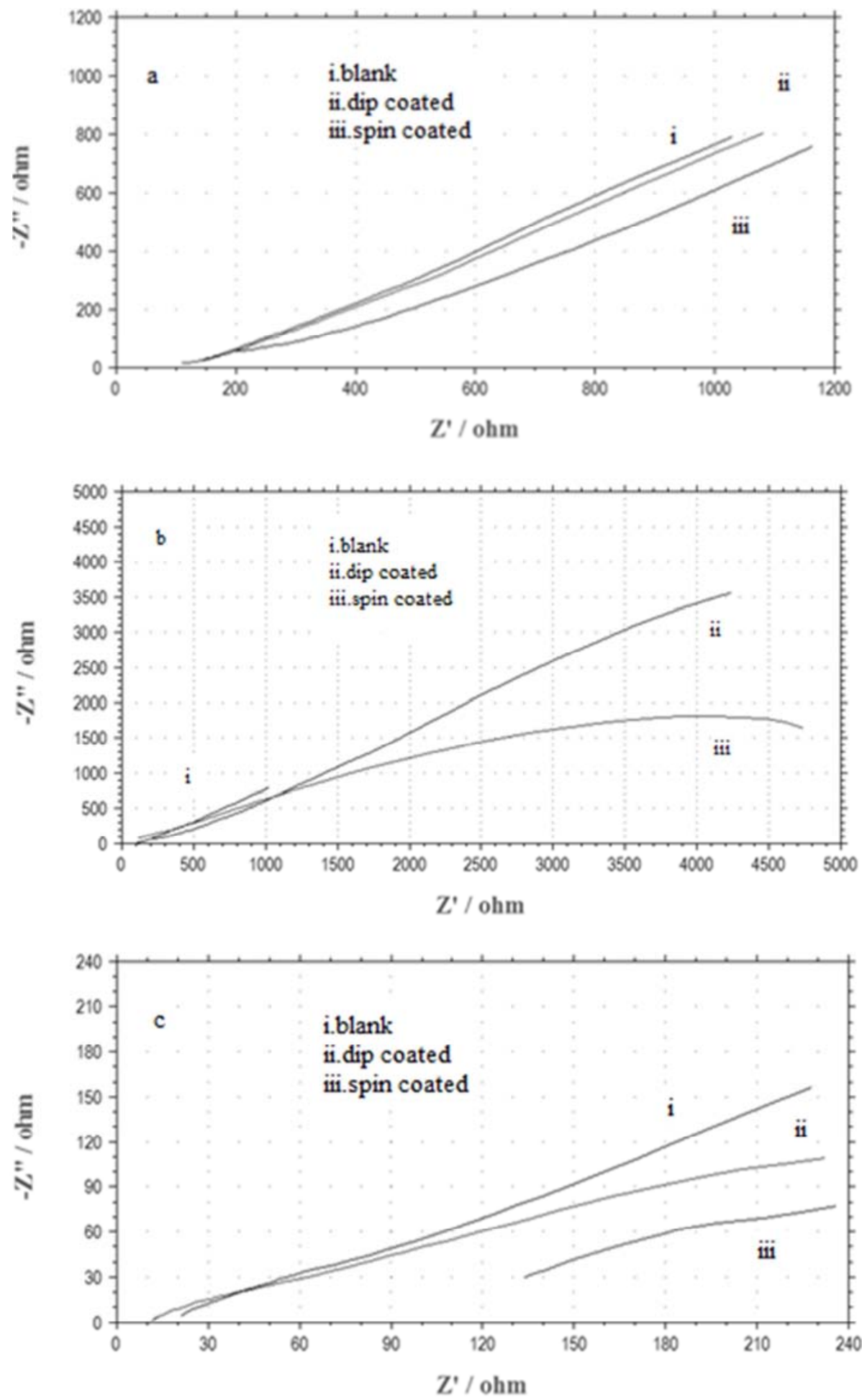

Figure 10. Impedance plot for (a) P, (b) PR, (c) PRZn dip and spin coated $M S$ in $3.5 \% \mathrm{NaCl}$ at $25^{\circ} \mathrm{C}$. 
Table 10. C. V parameters of P, PR, PRZn dip and spin coated $M S$ in $3.5 \% \mathrm{NaCl}$ at $25^{\circ} \mathrm{C}$.

\begin{tabular}{llll}
\hline $\mathbf{1 0} \%$ Conc & $\mathbf{( - )} \mathbf{E}_{\text {corr }}(\mathbf{V})$ & $\mathbf{I}_{\text {corr }}(\mathbf{A})$ & I.E $(\mathbf{\%})$ \\
\hline Blank & 0.0048 & $2.98 * 10^{-3}$ & - \\
P dip coated & 0.0013 & $3.46^{*} 10^{-4}$ & 85 \\
P spin coated & 0.0085 & $3.75 * 10^{-4}$ & 90 \\
PR dip coated & 0.0015 & $3.16^{*} 10^{-4}$ & 88 \\
PR spin coated & 0.0095 & $4.15^{*} 10^{-4}$ & 92 \\
PRZn dip coated & 0.0019 & $5.19 * 10^{-4}$ & 93 \\
PRZn spin coated & 0.0176 & $6.44 * 10^{-4}$ & 98 \\
\hline
\end{tabular}
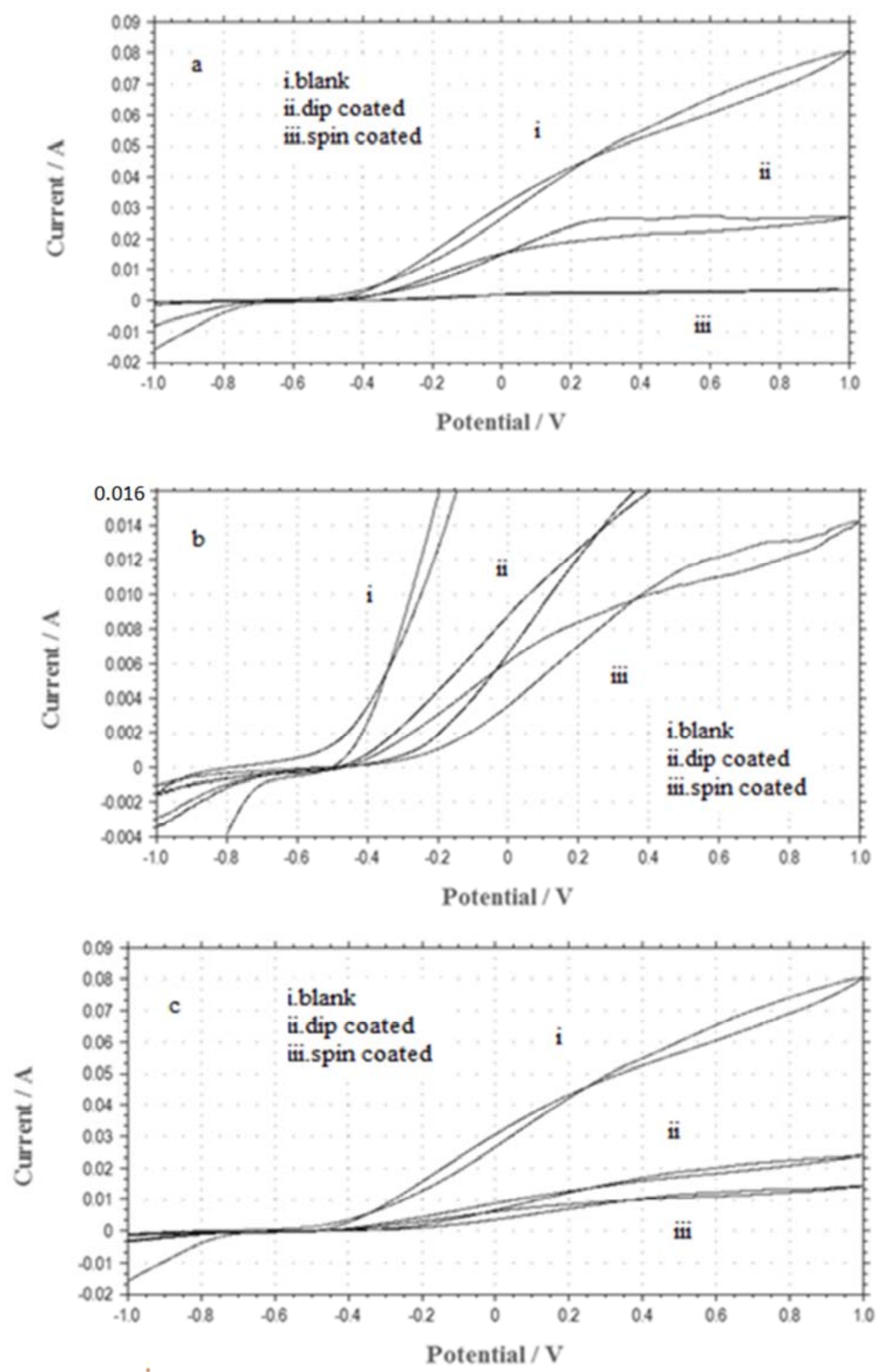

Figure 11. Cyclic Voltammogram for (a) P, (b) PR, (c) PRZn dip and spin coated MS in $3.5 \% \mathrm{NaCl}$ at $25^{\circ} \mathrm{C}$. 
The comparison between the efficiency of spin and dip coated specimens were analyzed by using Tafel, Impedance and $\mathrm{CV}$ analysis and the datas are presented in Tables 8, 9 \& 10 and Figures $9,10 \& 11$. It is noticed that the $\mathrm{E}_{\text {corr }}$ and $\mathrm{I}_{\text {corr }}$ values are slight increases for spin coated specimens than dip coated and the inhibition efficiency is more for spin coated one. The same inference was obtained for the Impedance and CV results and increase in ohmic resistance for spin coated specimens than dip coated and it is mainly due to nano fiber formation with an increased I. E for spin coated specimens. Thus for coating and corrosion protection activity spin coating is more advantageous than dip coated specimens.

\subsubsection{Reproducibility Test}

Figures 12, $13 \& 14$ and Tables 11, 12 and 13 illustrate that the reproducibility of the tested curves of PRZn under Tafel, impedance and CV studies respectively. From the representations it is clear that the corrosion potential, corrosion current, $\mathrm{R}_{\mathrm{ct}}$ and $\mathrm{C}_{\mathrm{dl}}$ values slightly get varied while performing the tests at second and third trials with fresh $3.5 \%$ $\mathrm{NaCl}$ ever trial but using the same $10 \%$ PRZn coated MS specimen. Thus $10 \%$ PRZn provide a better corrosion resistant activity due to the self-healing as well as sacrificial anodic properties of $\mathrm{ZnO}$. [13].

Table 11. Reproducibility tested datas of PRZn coated $\mathrm{MS}$ in $3.5 \% \mathrm{NaCl}$ at $25^{\circ} \mathrm{C}$.

\begin{tabular}{llll}
\hline Reproducibility test & $(-) \mathbf{E}_{\text {corr }}(\mathbf{V})$ & $\mathbf{I}_{\text {corr }}(\mathbf{A})$ & I. E (\%) \\
\hline Blank & 0.7645 & $2.23 * 10-4$ & - \\
1 st trial & 0.4326 & $7.12 * 10-6$ & 98 \\
2nd trial & 0.4536 & $7.24 * 10-5$ & 97 \\
3rd trial & 0.4536 & $7.24 * 10-5$ & 97 \\
\hline
\end{tabular}

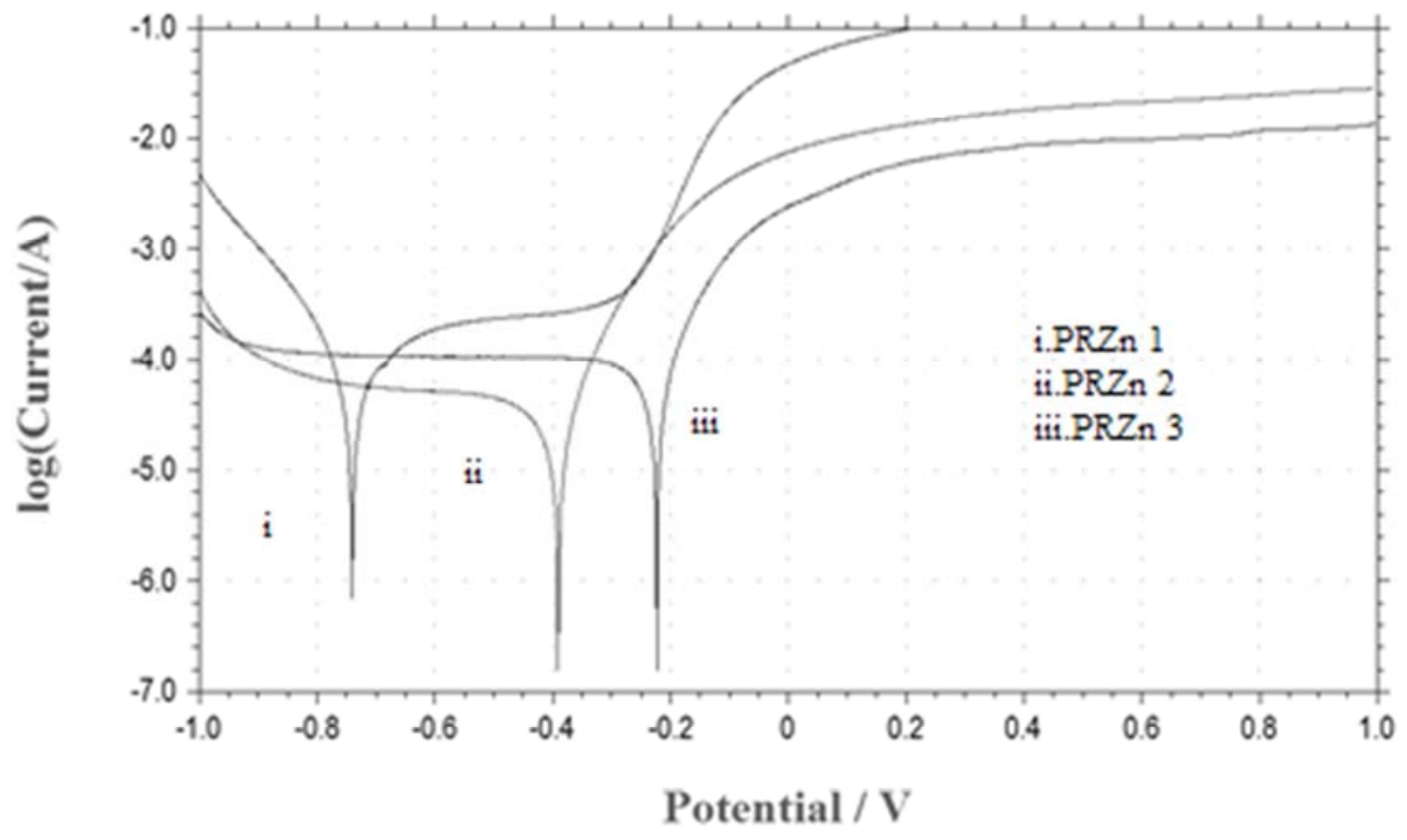

Figure 12. Reproducibility test for PRZn coated MS in $3.5 \% \mathrm{NaCl}$ (Tafel plot) $25^{\circ} \mathrm{C}$.

Table 12. Reproducibility impedance data of PRZn in $3.5 \% \mathrm{NaCl}$ at $25^{\circ} \mathrm{C}$.

\begin{tabular}{|c|c|c|c|}
\hline Reproducibility test & $\mathbf{R}_{\mathrm{Ct}}\left(\mathrm{Ohm} \mathrm{cm}^{2}\right)$ & $\mathrm{C}_{\mathrm{dl}}\left(\mathrm{Ohm} \mathrm{\textrm {cm } ^ { - 2 } )}\right.$ & I. E (\%) \\
\hline Blank & 9.11 & 0.0079 & - \\
\hline 1st trial & 86.35 & $1.56^{*} 10^{-9}$ & 99 \\
\hline $2^{\text {nd }}$ trial & 90.45 & $2.32 * 10^{-6}$ & 97 \\
\hline $3^{\text {rd }}$ trial & 90.45 & $2.32 * 10^{-6}$ & 97 \\
\hline
\end{tabular}




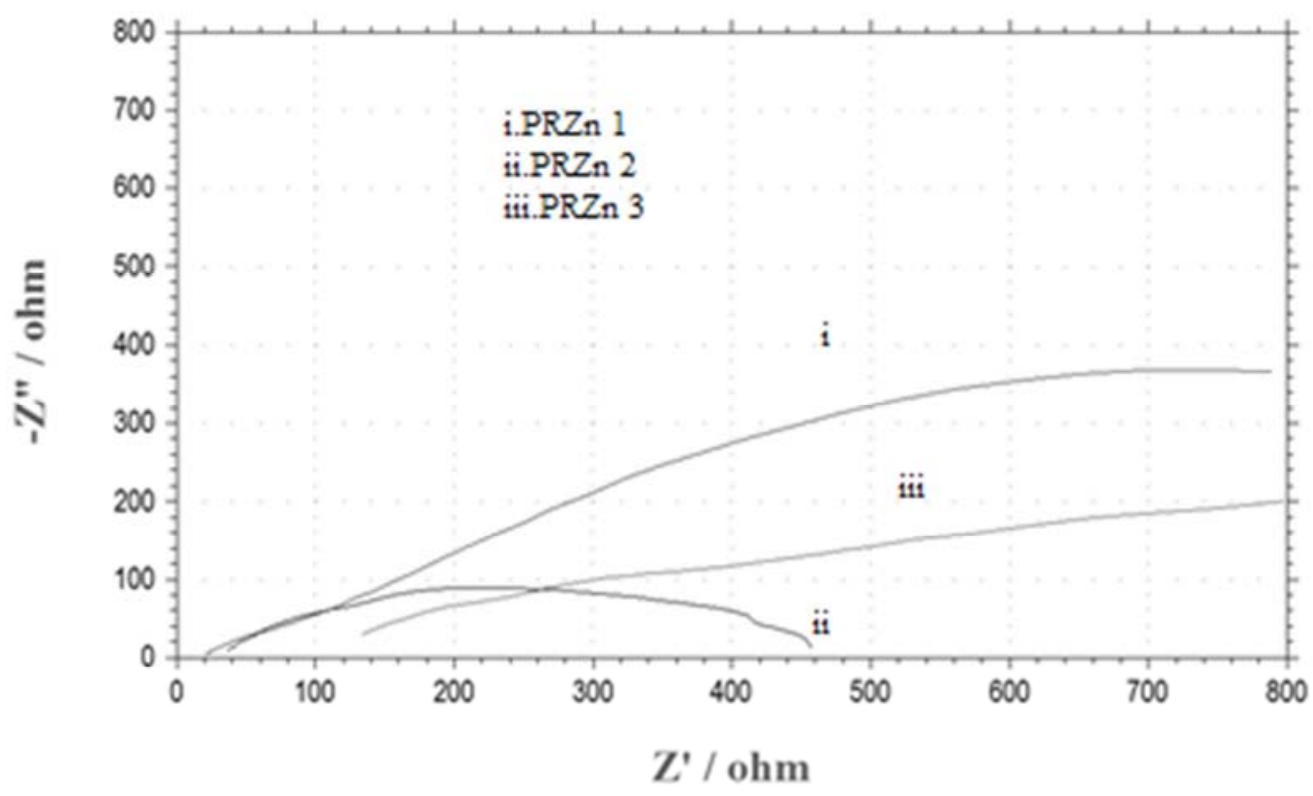

Figure 13. Reproducibility impedance curve for PRZn coated MS in $3.5 \% \mathrm{NaCl}$ at $25^{\circ} \mathrm{C}$

Table 13. Reproducibility $\mathrm{CV}$ data of PRZn in $3.5 \% \mathrm{NaCl}$ solution at $25^{\circ} \mathrm{C}$.

\begin{tabular}{llll}
\hline Reproducibility test & $(-) \mathbf{E}_{\text {corr }}(\mathbf{V})$ & $\mathbf{I}_{\text {corr }}(\mathbf{A})$ & I. E $(\%)$ \\
\hline Blank & 0.0045 & $2.98 * 10^{-3}$ & - \\
1 st trial & 0.0005 & $1.89 * 10^{-4}$ & 91 \\
$2^{\text {nd }}$ trial & 0.0005 & $1.89 * 10^{-4}$ & 91 \\
$3^{\text {rd }}$ trial & 0.0013 & $3.16^{*} 10^{-3}$ & 90 \\
\hline
\end{tabular}

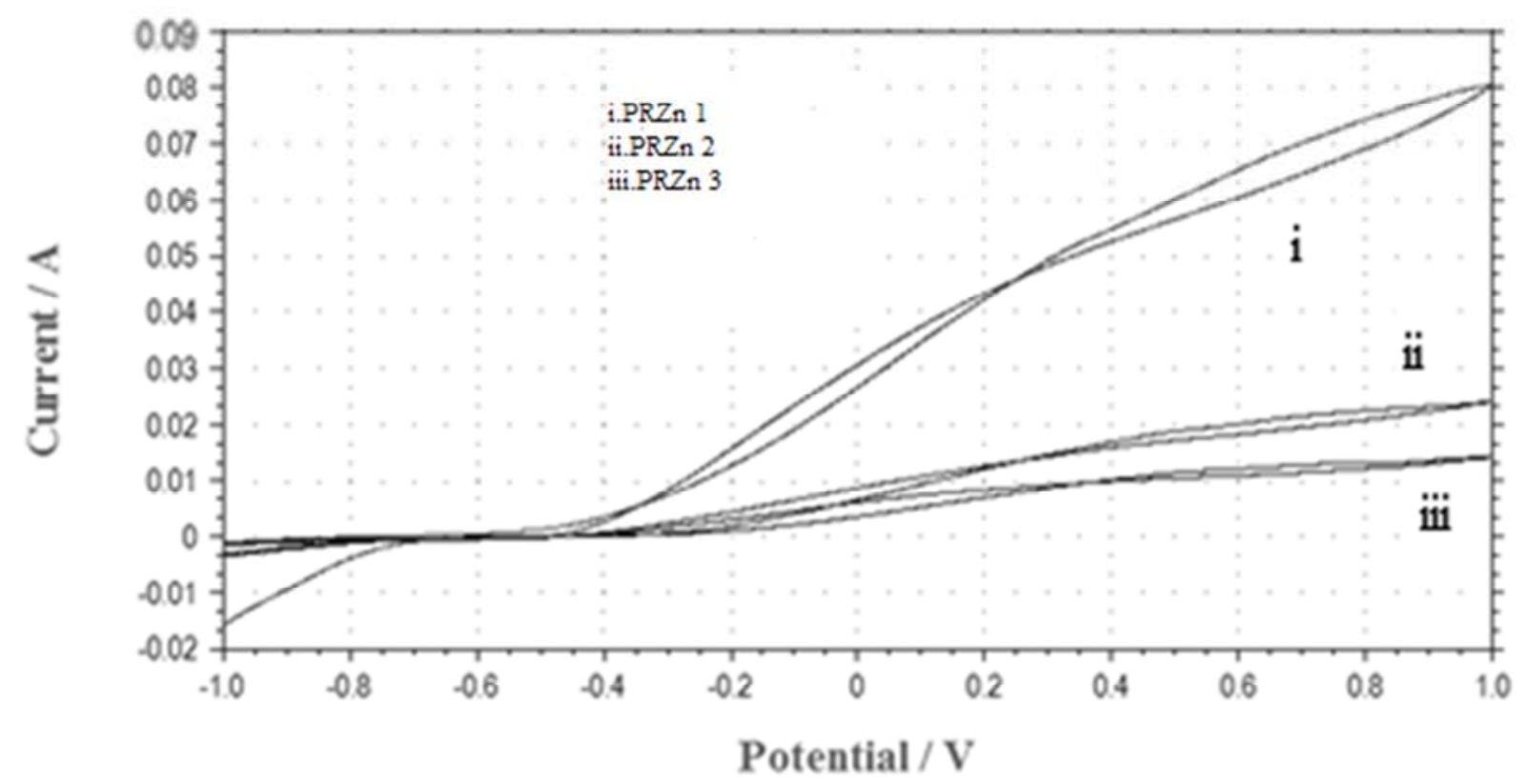

Figure 14. Reproducibility cyclic voltammogram for PRZn coated MS in $3.5 \% \mathrm{NaCl}$ at $25^{\circ} \mathrm{C}$.

\subsection{Comparison of PRZn and Paint Coatings}

On comparing effectiveness of PRZn coating over paint coating on $\mathrm{MS}$ in normal humid and $3.5 \% \mathrm{NaCl}$ environments, a visual observation was carried out. It was found that thickness of coating with paint on MS specimen is high with less durability than polymer coat. Peel-off of the paint coated specimen and rusting was taken place at normal atmosphere within 3 months duration. But the $3.5 \% \mathrm{NaCl}$ exposed polymer-resin coated specimen has a low thickness, high durability and rusting was not seen. It was notice to with stand for long duration in marine environment. 

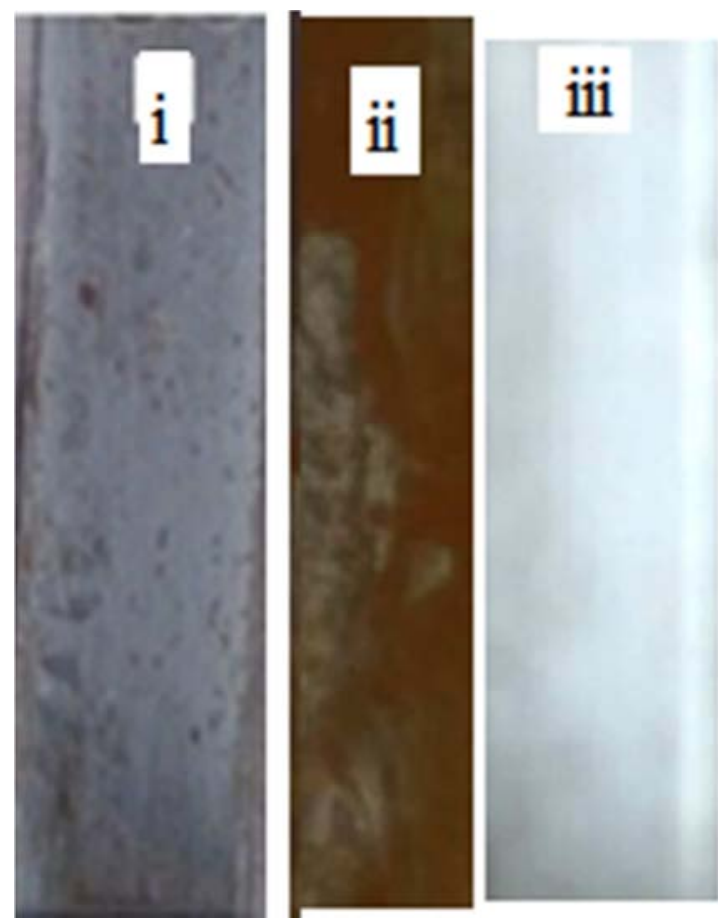

Figure 15. Comparison of MS coated with (i) blank (ii) paint (iii) PRZn.

\subsection{Thermogravimetric Analysis}

The TGA curves for PRZn and PMMA sample is shown in Figures $16 \& 17$ respectively. Having a comparison of TGA curves of PRZn spin coated and pure PMMA Figure 17, we find that pure PMMA have a transition temperature around 250 to $400^{\circ} \mathrm{C}$ while the addition of resin and $\mathrm{ZnO}$ nano particle to PMMA, the peak varies above $500^{\circ} \mathrm{C}$. This clearly shows the effect of resin and $\mathrm{ZnO}$ on pure PMMA. The weight loss in the first step in Figure 16 corresponds to the evaporation of water $\left(90-100^{\circ} \mathrm{C}\right)$. The second step weight loss peak starting at above $290^{\circ} \mathrm{C}$ is due to the crystal cleavage and attributed to the melting and degradation of different morphological components of PMMA and coincide with the temperature range over which a number of defined paralysis reaction takes place in PMMA. The hydrogen bond of $\mathrm{CH}_{3}$ ruptures and ordered regions of PMMA undergo a solid to liquid phase change [14]. From this temperature range $290{ }^{\circ} \mathrm{C}$ to $350{ }^{\circ} \mathrm{C}$, the mass loss $0.8307 \% /{ }^{\circ} \mathrm{C}$ is due to degradation polymer-nano particle and the residual percentage is $83.9 \%$. It is characterized by the DTA peak analysis presence of the typical melting endotherm at $320^{\circ} \mathrm{C}$ coincide with the temperature range over which a number of defined reactions that take place in PRZn. This result shows that the coating can be with stand upto $250^{\circ} \mathrm{C}$, which is greater than the onset temperature of $\operatorname{PMMA}\left(171^{\circ} \mathrm{C}\right)$.

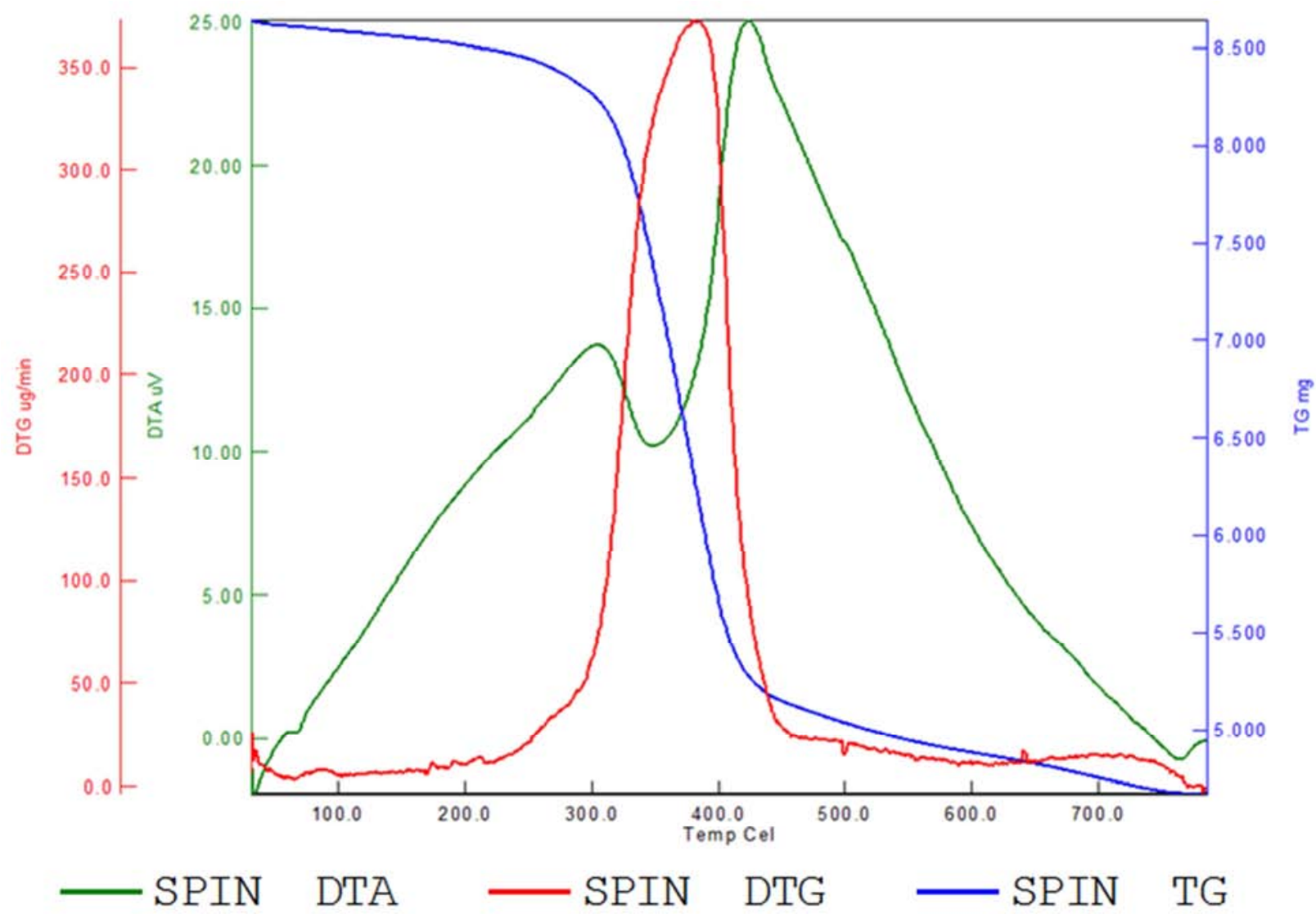

Figure 16. TGA-DTA curve of $10 \%$ spin coated PRZn. 


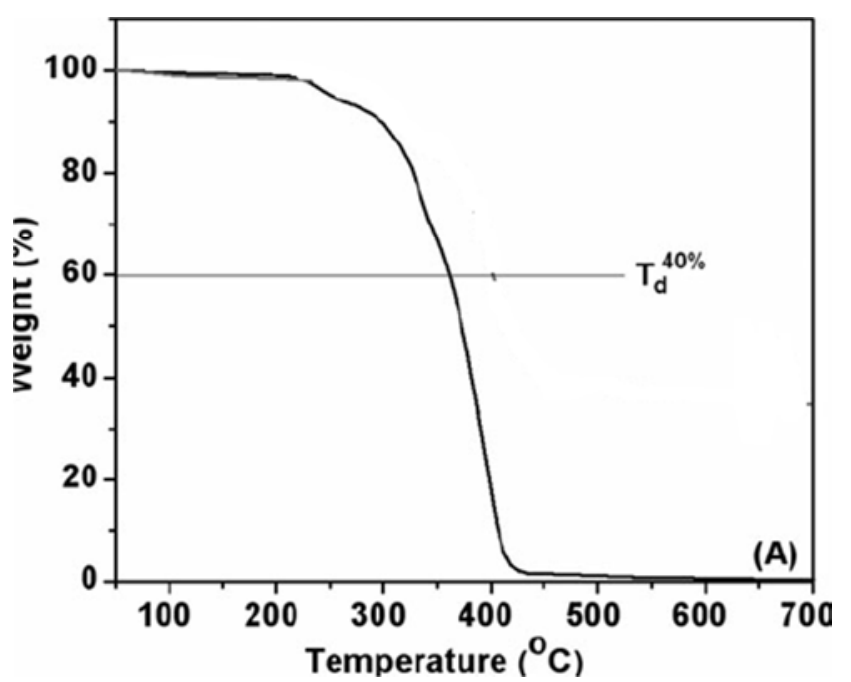

Figure 17. TGA curve of pure PMMA (Springer link).

\subsection{Characterization of Coated Material}

\subsubsection{XRD}

Figure $18 \mathrm{a} \& 18 \mathrm{~b}$ shows the XRD analysis of the PRZn dip and spin coated obtained from $20^{\circ}-60^{\circ} \mathrm{C}$ with the scan range of $2 \theta \mathrm{min}^{-1}$. Dip coated PRZn graph (figure 18a) shows high intense peaks at $14.58^{\circ}$. It is mainly attributed by the amorphous nature of the PMMA and resin. The peaks at $2 \theta$ includes $32.68^{\circ}, 36.54^{\circ}, 82.28^{\circ}$ can be indexed to (100), (102), (200) respectively. While the $2 \theta$ values for the spin coated specimen (figure $18 \mathrm{~b}$ ) includes $31.74^{\circ}, 34.39^{\circ}, 36.23^{\circ}$, $47.52^{\circ}, 56.58^{\circ}$ and $62.87^{\circ}$ can be indexed to (100), (002), (101), (102), (103) and (200) respectively. The crystal planes are in well accordance with the JCPDS 36-1451 of the crystal planes. When PR coated with $\mathrm{ZnO}$, the position of the peak $( \pm 1)$ slightly varying. Here the film peak shows a peak broadening compared to figure 1 and that shows the effect of polymer over $\mathrm{ZnO}$ in corrosion protection.
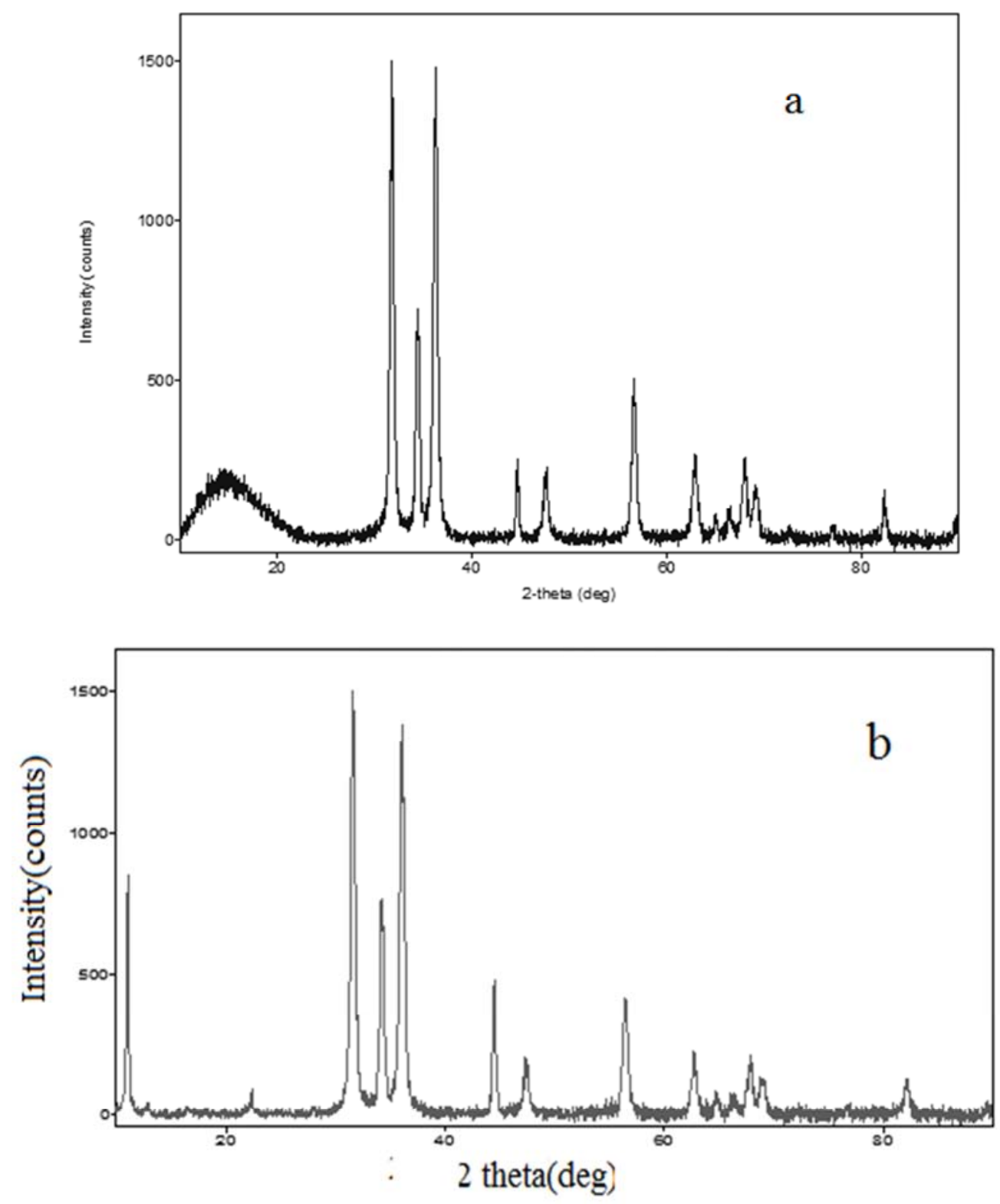

Figure 18. XRD spectra of MS coated specimen in (a) $10 \%$ PRZn dip coated, (b) $10 \%$ PRZn spin coated at $25^{\circ} \mathrm{C}$. 


\subsubsection{FTIR}

FTIR spectrum of $10 \%$ PRZn results is presented in Figure 19. Peak at $700,1300,1250$ and $2100 \mathrm{~cm}^{-1}$ is attributed to the C-H stretching (meta substitution), C-O stretching, C-H bending, $\mathrm{C}-\mathrm{H}$ asymmetrical stretching of $\mathrm{CH}_{3}$ group. While peak at $3446.9 \mathrm{~cm}^{-1}$ attributes to $\mathrm{O}-\mathrm{H}$ stretching vibration and $1639.5 \mathrm{~cm}^{-1}$ to $\mathrm{C}=\mathrm{C}$ stretching. These results reveal the presence of many functional groups in polymer, which helps the adsorption of the molecule on metal surface and protection it from corrosion.

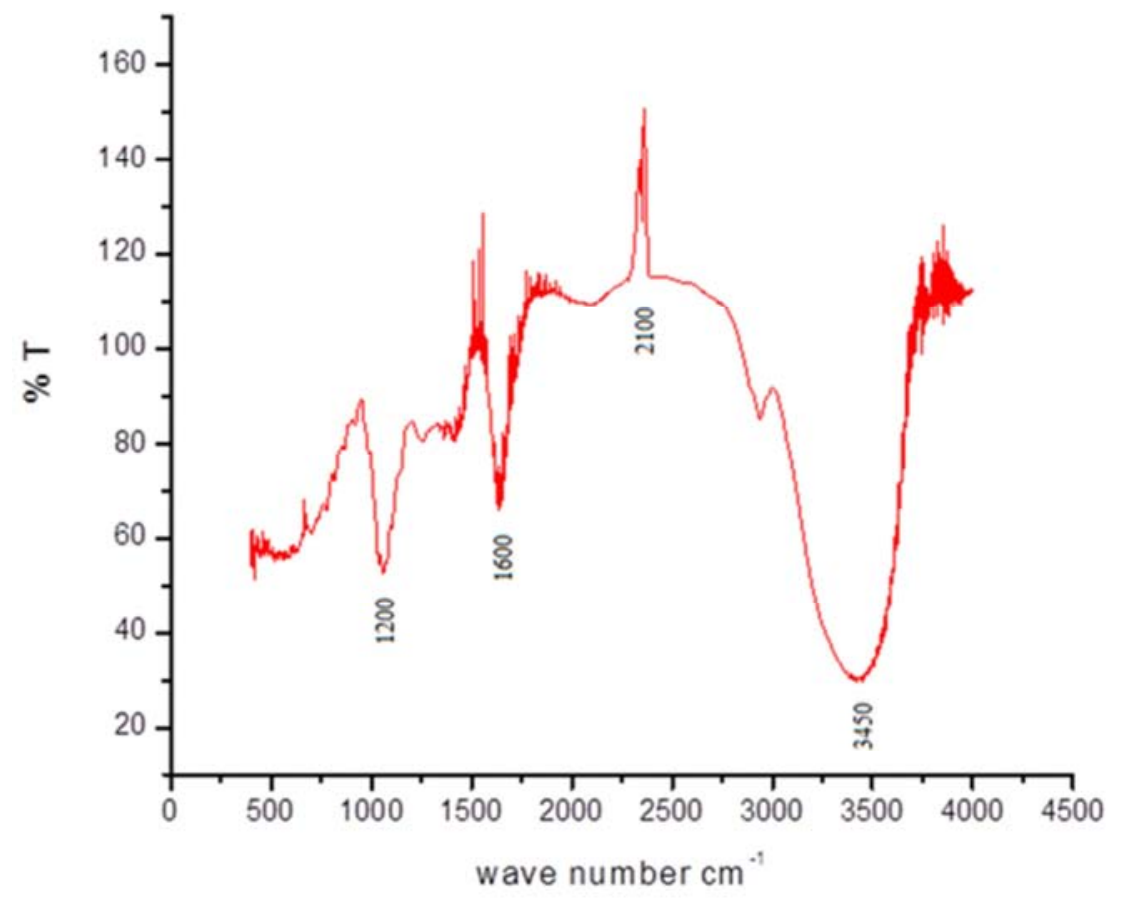

Figure 19. FTIR spectra for dip coated specimen $10 \%$ PRZn.

\subsubsection{Zeta Potential}

The stability and dispersibility of $\mathrm{ZnO}$ constituent molecules in PR combination were estimated using zeta potential measurement and presented in Figure 20. The surface potential of $\mathrm{PRZn}$ solution is $-72.6 \mathrm{eV}$, average particle dispersion size is $150 \mathrm{~d}$. $\mathrm{nm}$ and its zeta potential is -
$99 \mathrm{eV}$. This increase in negative charge and smaller size of the particle distribution in PRZn is due to the high negative surface, which reflects the high stability and aggregation of the particle on metal surface because of repulsion force between adjacent molecules. [15]

\section{Size Distribution by Intensity}

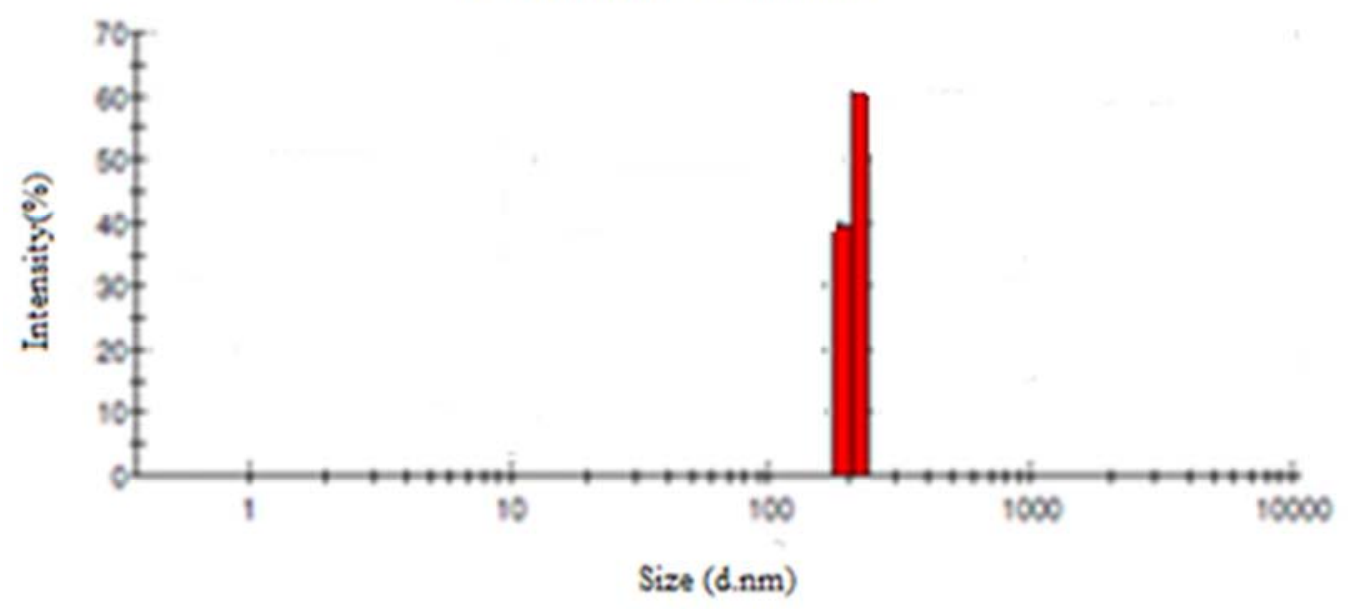

Figure 20. Zeta potential spectra for $10 \%$ PRZn. 
Profilometer analysis result is presented in Figure 21. It shows the comparison between the dip coated paint and polymer on MS surface. From the graph, it is clear that the thickness of paint coating is more than that of polymer coating. The thickness of paint coating with respect to its diameter ratio along the range of $400 \mu \mathrm{m}$ and the polymer coated specimen thickness only in range of $315 \mu \mathrm{m}$. The surface texture and roughness is also measured, where the polymer coated specimen show controlled roughness which is more desirable while paint coated specimen show more roughness. Thus with respect to coating polymer can be utilized more than paint.

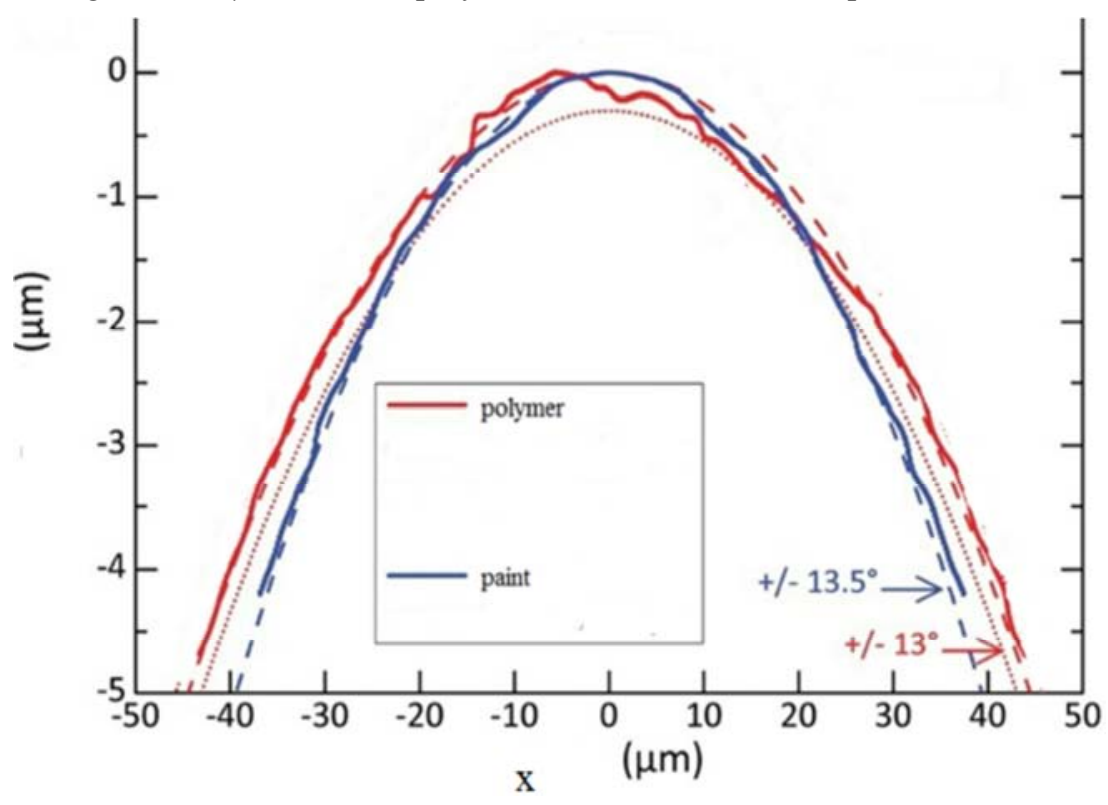

Figure 21. Profilometer analysis of paint and polymer dip coated specimen.

\subsubsection{FESEM}

FESEM micrograph of MS specimen coated with $10 \%$ PRZn spin coated and dip coated was analyzed under different magnification of $10000-40000 \mathrm{X}$ and presented in Figure $22 \mathrm{a}$ and $22 \mathrm{~b}$. It is noted that in the spin coated MS using PRZn have more nano $\mathrm{ZnO}$ particle than dip coated one. It is observed that the nano $\mathrm{ZnO}$ particle get encapsulated by polymer and resin. PRZn dip coated specimen surface seems to be coated with an amorphous and spherical shape with a rough texture. Both the dip and spin coated film surface are observed non -porous, adherent film and there is no scratch, bulging or peel -off takes place. [16]

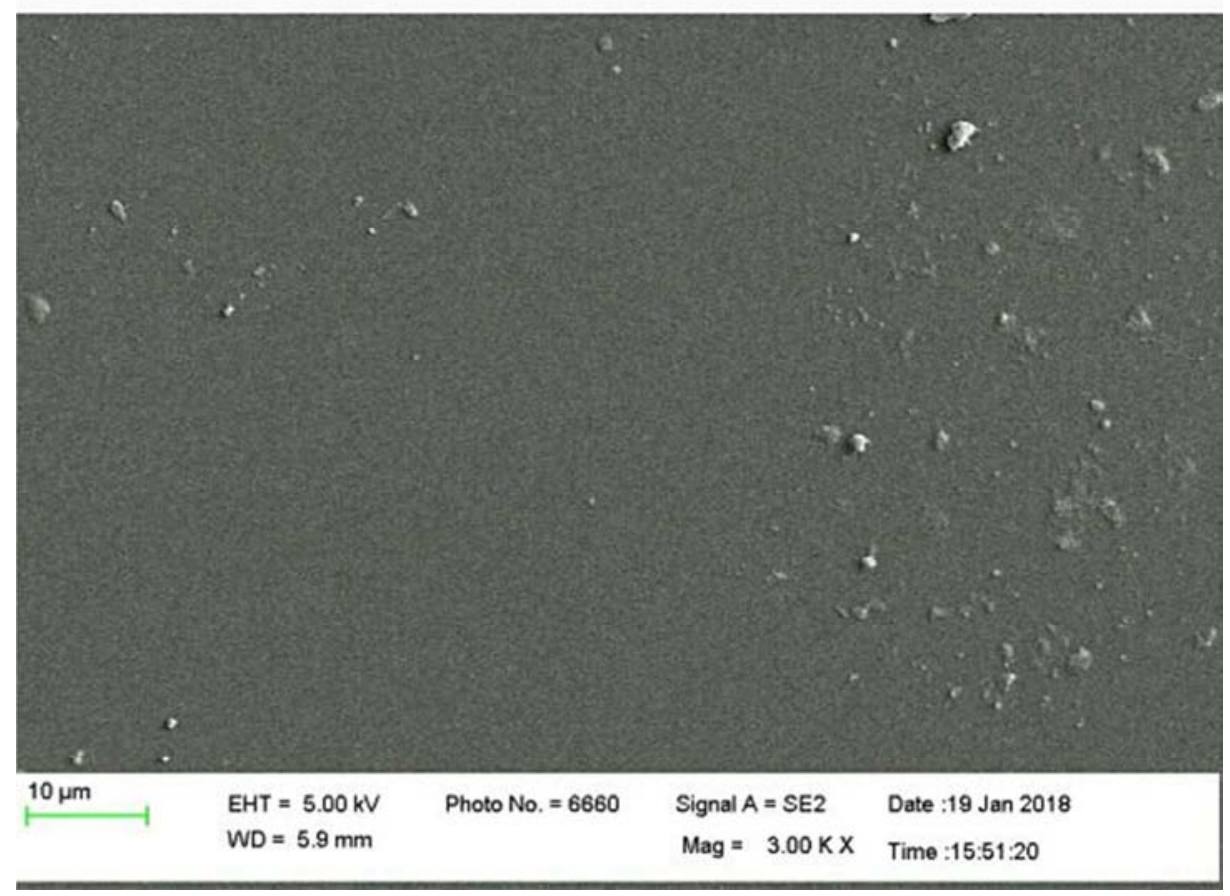




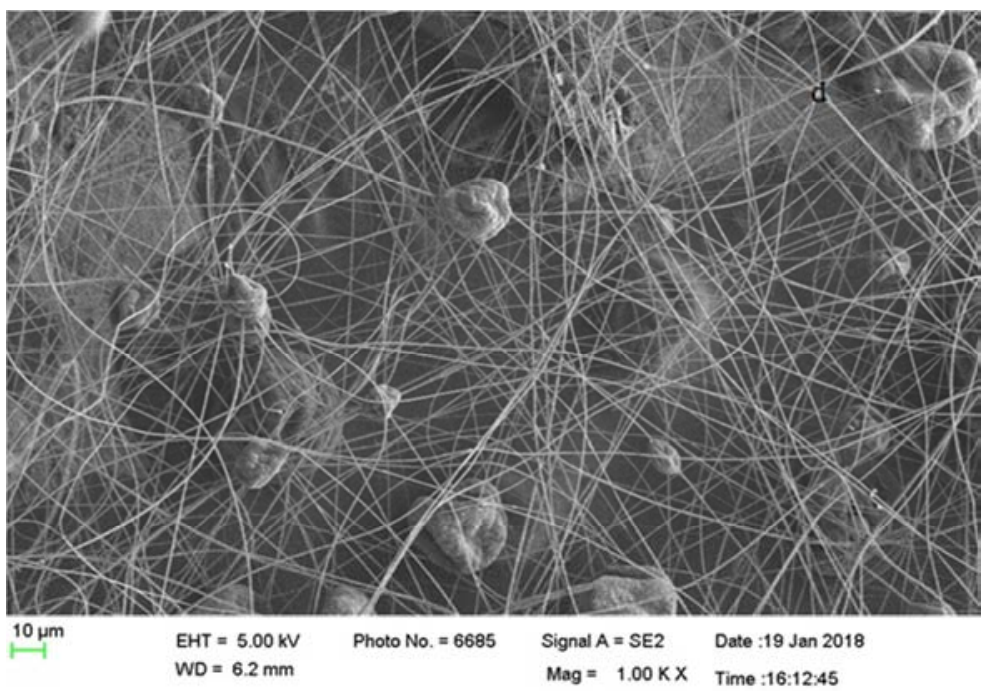

Figure 22. FESEM analysis result for MS with 10\% PRZn (a) dip \& (b) spin coated.

\subsection{3. $E D X$}

The EDX results obtained for $10 \%$ PRZn dip and spin coated MS surface are shown in Figure 23 a \& $23 \mathrm{~b}$ and Tables $14 \& 15$. It is seen that elements of $\mathrm{C}, \mathrm{O}, \mathrm{Fe} \& \mathrm{Zn}$ are identified. The percentage composition of $\mathrm{C}, \mathrm{Zn}, \mathrm{O}$ and $\mathrm{Fe}$ is comparable to the major constituents present in PRZn. This result is found to be in concordant with the other analysis.
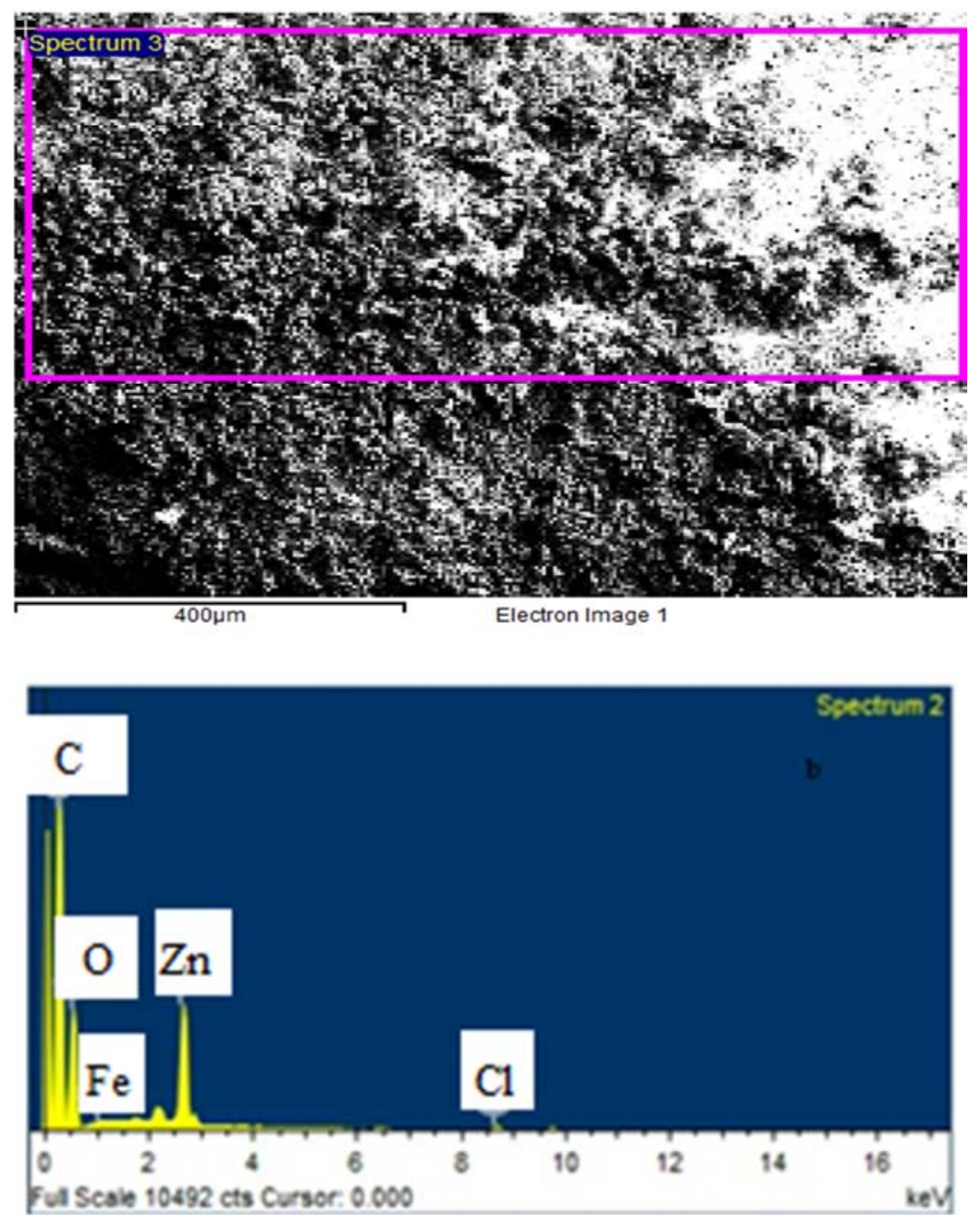

Figure 23. EDX spectra and elemental composition for 10\%PRZn dip coated sample. 
Table 14. EDX elemental composition of PRZn dip coated specimen.

\begin{tabular}{llll}
\hline Element & Weight\% & Atomic\% & Compound\% \\
\hline $\mathrm{C}$ & 26.95 & 33.21 & 98.75 \\
$\mathrm{Fe}$ & 0.09 & 0.03 & 0.12 \\
$\mathrm{Zn}$ & 0.22 & 0.05 & 0.27 \\
$\mathrm{Au}$ & 0.53 & 0.04 & 0.59 \\
$\mathrm{O}$ & 71.96 & 66.56 & \\
\hline
\end{tabular}
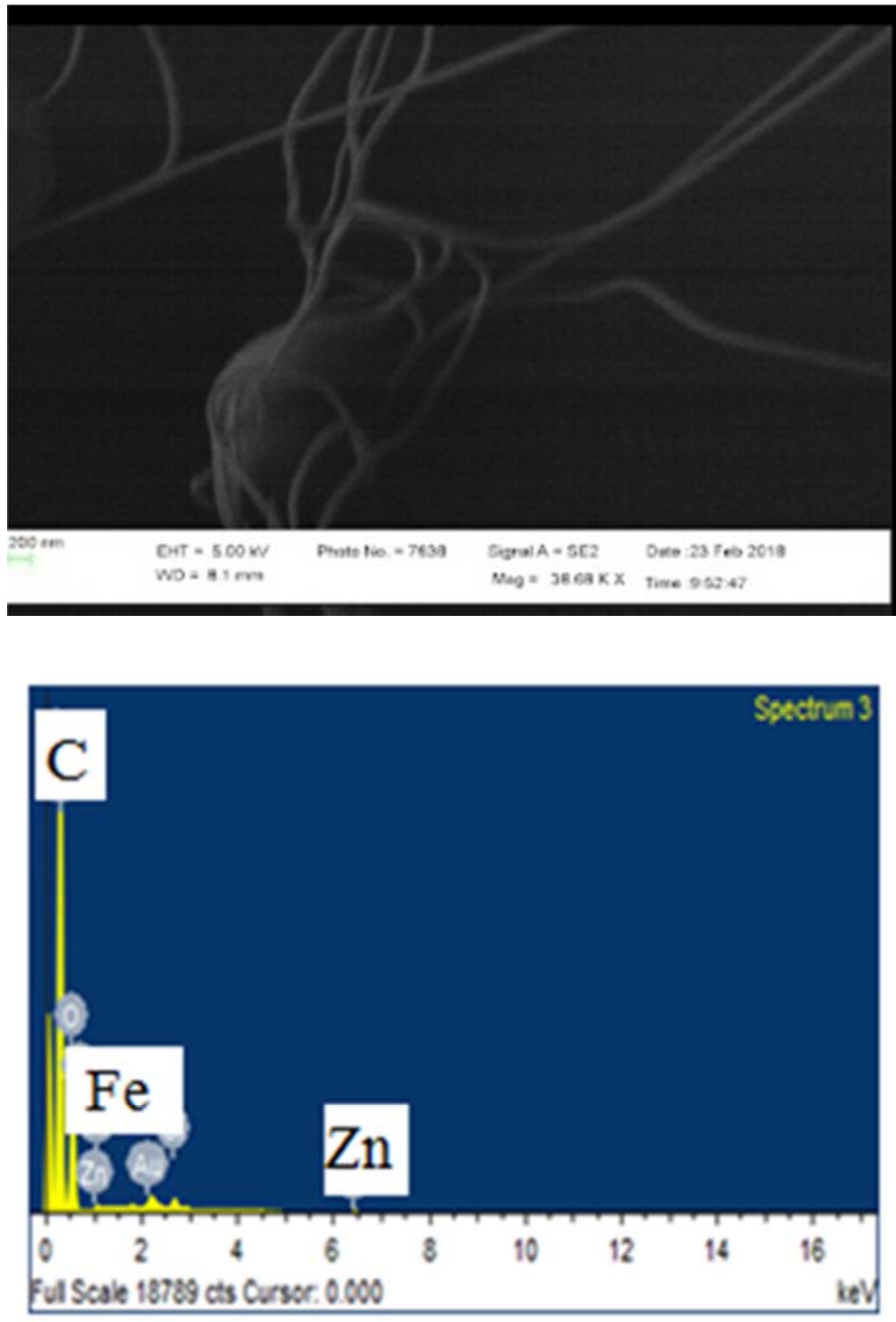

Figure 24. EDX spectra and elemental composition for 10\%PRZn spin coated sample.

Table 15. EDX elemental composition of PRZn spin coated specimen.

\begin{tabular}{llll}
\hline Element & Weight\% & Atomic\% & Compound\% \\
\hline $\mathrm{C}$ & 26.95 & 33.21 & 98.75 \\
$\mathrm{Fe}$ & 0.09 & 0.03 & 0.12 \\
$\mathrm{Zn}$ & 0.22 & 0.05 & 0.27 \\
$\mathrm{Au}$ & 0.53 & 0.04 & 0.59 \\
$\mathrm{O}$ & 71.96 & 66.56 & \\
\hline
\end{tabular}




\subsubsection{Contact Angle}

Contact angle was measured for PRZn dip and spin coated specimens and compared with the blank specimen using Sessile drop method and represented in Figure 25 (a-c). These photographs showed that the less wetting property of adsorbed molecules on MS by dip coated and no wetting of spin coated MS sample surface when compared to blank. Figure 25a shows a blank specimen on the addition of water droplet immediately spread out on MS surface inferred its hydrophilic nature. Water drop is partially merged and inferred that the partial hydrophilic in nature of the MS surface after dip coated. Figure $25 \mathrm{~b}$, its interfacial tension (IFT) value was measured $2.67 \mathrm{mN} / \mathrm{m}$. While the specimen after spin coated Figure 25c, the water drops being completely floated and being hydrophobic in nature and its contact angle value is $134.7^{\circ}$ and the IFT value is $2.74 \mathrm{mN} / \mathrm{m}$ ) shows an angle of $134.7^{\circ}$ and depicts the Lotus effect. [17]This shows that for spin coated surface has higher the interfacial tension value, more energy required to merge water drops on the metal surface due to its hydrophobicity and it has more repulsive force than dip coated surface.[18]
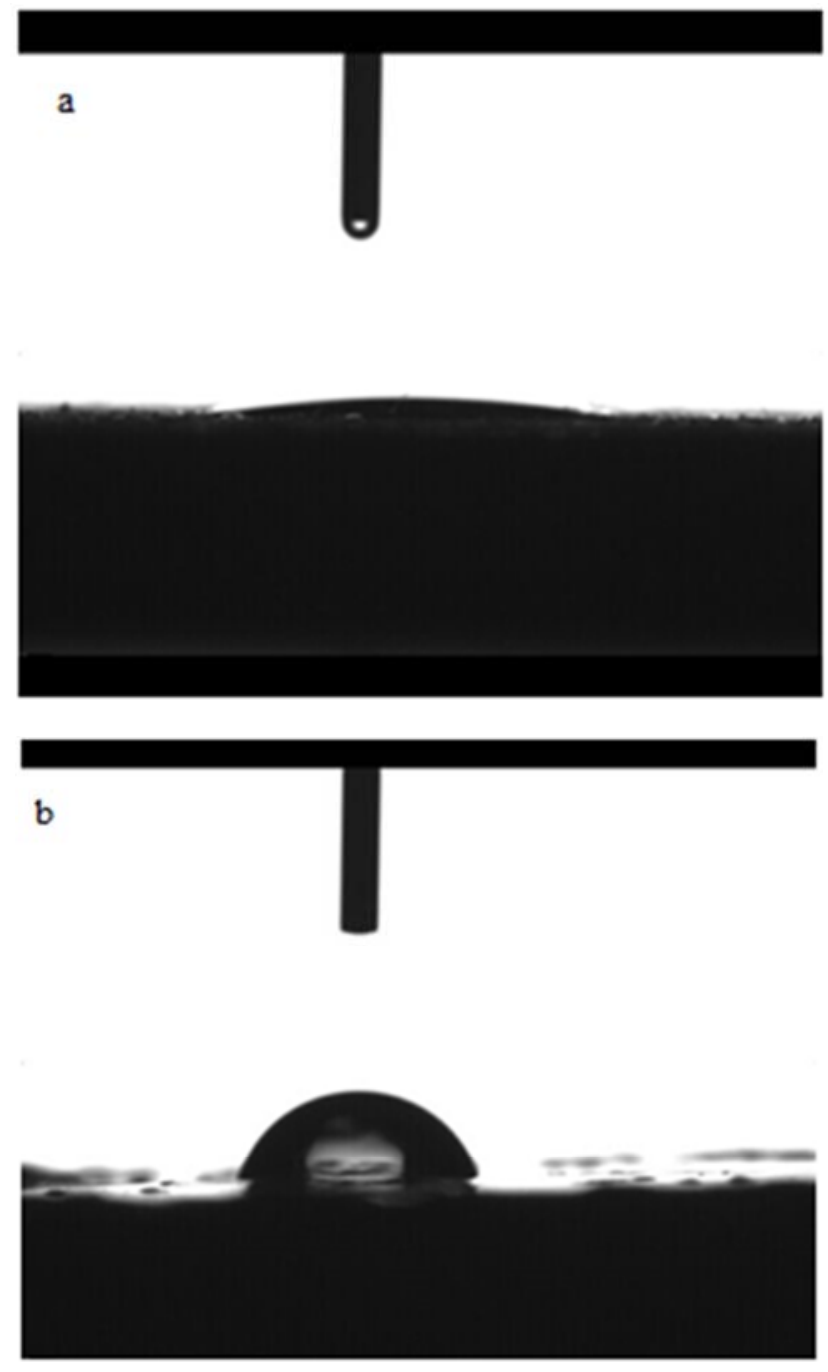

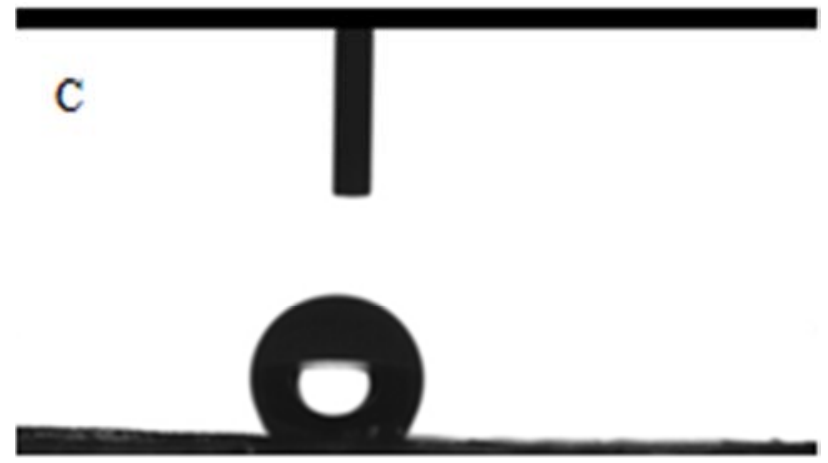

Figure 25. Contact angle for MS coated with (a) blank specimen (b) $10 \%$ PRZn dip coated and (c) $10 \%$ PRZn spin coated.

\section{Conclusion}

From the present study, we conclude that the PRZn, as a nano coating material, is able to provide excellent corrosion protection for MS comparing to only polymer and PR combination for dip and spin coating in marine environment. The effect of concentration shows that there is an increase in the I. E with an increase in concentration up to $10 \%$ and after which there will be decrease due to peel off, pit formation or bulging of the coated film. The results arrived from potentiodynamic polarization results indicate that the polymer combination and a natural inhibitor with a nano particle act as mixed type inhibition of corrosion with high IE values due to the adsorption of chemical constituents on metal surface and also due to synergistic effect. Comparison with the I. E of spin and dip coated specimens show that spin coated specimens have higher I. E and high corrosion protection activity and hence choosing a spin coating coating for the activity would be more advantageous. Reproducibility test shows that PRZn has a low loss weight percent compared to $\mathrm{P}$ and PR due to self -healing and sacrificial anode on the use of $\mathrm{ZnO}$ nanoparticles to PR. Thus PRZn provides a better anti-corrosion activity. The characterization and surface analysis by XRD, FTIR and SEM of the Nano particle shows that the synthesized particle is nano in size while the XRD, FTIR and Zeta potential of PRZn proves the presence of major chemical constituents present in the coated film and adsorbed and offer more corrosion protection on MS surface. The SEM analysis of the PRZn spin coating shows the formation a nano fiber and its efficiency in protecting the specimen from corrosion. Profilometer analysis proves the high thickness and roughness of paint coated specimen when compared to polymer coated specimen. Contact angle studies proves the coated PRZn film being spin coated is more hydrophobic nature with high IFT values that repulse the water molecule on MS surface there by provide highly protective than the PRZn dip coated film. Finally the PRZn combination of a low cost polymer, natural inhibitor resin and easily synthesizable $\mathrm{ZnO}$ Nano particle is non-toxic can be used coating for metals. Thus the combination of PRZn has found more advantageous in corrosion protection. 


\section{Acknowledgements}

We are grateful to Amrita Vishwa Vidyapeetam, Coimbatore, Tamil Nadu, India for help to carry out this work. The author would like to thank Prof. T. Ramachandran for giving their valuable suggestion for this research and biosensor lab staffs and Chemistry Department lab staffs.

\section{References}

[1] ABDEL HAMEED R. S., Nano Composite as Corrosion Inhibitor for Steel Alloy in Different Corrosive Media, Advances in Applied Science Research, 4 (3),(2013), 126-129.

[2] AGGARWAL L. K., Anticorrosive Properties of EpoxyCardinol Resin Based Paints, Progress in Organic Coatings, 59, (2007), 76-80.

[3] ATTA A. M., Corrosion Inhibition of Nano Composite Based on Acrylamide Copolymers for Steel, Digest Journal of Nano materials and Bio structures, (2014), 627-639.

[4] AWAD G. H., Effect of Some Plant Extracts on the Corrosion of Mild Steel in $\mathrm{NaCl}$, Proceedings on the $6^{\text {th }}$ European Symposium on Corrosion Inhibitors (ESEIC), Ann. Univ. Ferrara, 1985, 8, 385-395.

[5] CHANCHAL KUMAR KUNDU., WEI WANG., SHUN ZHOU., XIN WANG AND YUAN HU., A Green Approach to Constructing Multilayered Nano Coating for Flame Retardant of Polyamide 66 Fabric Chitosan and Sodium alginate, Carbohydrate Polymers, 166,(2017), 131-138.

[6] CONG-CONG JIANG., A Review on the Application of Inorganic nanoparticles in Chemical Surface Coatings on Metallic Substrates, RSC Advances, 7, (2016), 7531.

[7] MARIA CANTARELLA., Novel synthesis of ZnO/PMMA Nano composites for photo catalytic applications, scientific reports, 6, (2016), 12-16.
[8] SUSAI RAJENDRAN., A combinatorial approach to corrosion inhibition of alloy, Research scholar, 9, (2017), 216235 .

[9] HONH R. Y., QIAN J. Z., Synthesis and characterization of PMMA grafted ZnO nanoparticles, Powder Technology, 163, (2006), 160- 168

[10] HARISH. S. BHAT., Studies on Characterization of Doped $\mathrm{ZnS}$ nanoparticles, Journal of nanotechnology, 8, (2014), 1033-1039.

[11] TAIB HEAKAL F. E., Impedance studies of the inhibitive effect of benzotriazole on the corrosion of $\mathrm{Cu}$ in $\mathrm{NaCl}$ medium, Corr. Sci., 20, (1980), 887-898.

[12] HARUYAMA, Impedance studies on the corrosion of $\mathrm{Cu}$ in $\mathrm{NaCl}$ medium, Corr. Sci., 20, (1990), 1587-1898.

[13] KOVTYUKHOVA N. I., GORCHINSKIY A. D., and WARAKSA C., Self- assembly of nanostructured composite ZnO-polyaniline films, Mater. Sci. Eng. B, 424, (2000), 69-70.

[14] ELIHU. C. IHMS, Thermo gravimetric Analysis as a Polymer Identification Techniques, Journal of Forensic Sciences, 49(3),(2004), 505-510.

[15] CAO J. X., Synthesis and Characterization of PMMA, Nano science, 168, (2006), 172-176.

[16] YONG-FANG QIAN., Electro spinning of PMMA Nano fibers in different solvents, Iranian polymer journal; 19(2), (2010), 123-129.

[17] KALANTARIAN. A, Methodology for Contact angle, Corr. Sci., 25, (2009), 14146-14154.

[18] FRANK CHENG, Y., An intelligent coating doped with inhibitor encapsulated Nano containers for corrosion protection, Chemical engineering journal, (2017), 315, 537-551. 